\title{
Pharmacotherapies for chronic obstructive pulmonary disease: a multiple treatment comparison meta-analysis
}

This article was published in the following Dove Press journal:

Clinical Epidemiology

25 March 20II

Number of times this article has been viewed

\section{Edward J Mills' \\ Eric Druyts' \\ Isabella Ghement ${ }^{2}$ \\ Milo A Puhan ${ }^{3}$}

'Faculty of Health Sciences, University of Ottawa, Ottawa, Ontario, Canada;

${ }^{2}$ Ghement Statistical Consulting

Company, Richmond, British Columbia,

Canada; ${ }^{3}$ Department of Epidemiology,

Johns Hopkins Bloomberg School

of Public Health, Johns Hopkins

University, Baltimore, MD, USA
Correspondence: Edward Mills

Faculty of Health, Sciences,

43 Templeton, Ottawa,

ON KIN 6N5, Canada

Tel + I 7783178530

Email edward.mills@uottawa.ca
Background: Most patients with moderate and severe chronic obstructive pulmonary disease (COPD) receive long-acting bronchodilators (LABA) for symptom control. It is, however, unclear if and what drug treatments should be added to LABAs to reduce exacerbations, which is an important goal of COPD management. Since current guidelines cannot make strong recommendations yet, our aim was to determine the relative efficacy of existing treatments and combinations to reduce the risk for COPD exacerbations.

Methods: We included randomized clinical trials (RCTs) evaluating long-acting $\beta_{2}$ agonists (LABA), long-acting muscarinic antagonists (LAMA), inhaled glucocorticosterioids (ICS), and the phosphodiesterase-4 (PDE4) inhibitor roflumilast, and combinations of these interventions in moderate to severe COPD populations. Our primary outcome was the event rate of exacerbations. We conducted a random-effects Bayesian mixed-treatment comparison (MTC) and applied several sensitivity analyses. In particular, we confirmed our findings using a binomial MTC analysis examining whether a patient experienced at least one exacerbation event or not during the trial. We also used an additive assumption to calculate the combined effects of treatments that were not included in the systematic review.

Results: Twenty-six studies provided data on the total number of exacerbations and/or the mean annual rate of exacerbations among a combined 36,312 patients. There were a total of 10 treatment combinations in the MTC and 15 in the additive analysis. Compared with all other treatments, the combination of roflumilast plus LAMA exhibited the largest treatment effects, and had the highest probability ( $45 \%$ ) of being the best first-line treatment. This was consistent whether applying the incidence rate analysis or the binomial analysis. When applying the additive assumption, most point estimates suggested that roflumilast may provide additional benefit by further reducing exacerbations.

Conclusions: Using various meta-analytic approaches, our study demonstrates that depending on the choice of drug, combined treatments offer a therapeutic advantage.

Keywords: exacerbations, MTC analysis, clinical trials, roflumilast

\section{Introduction}

Chronic obstructive pulmonary disease (COPD) is a leading cause of morbidity and mortality throughout the world. ${ }^{1}$ Predominantly caused by tobacco smoke, which causes the airways to narrow, COPD leads to a limitation of the flow of air to and from the lungs. This causes shortness of breath. COPD results in an important reduction in a patient's quality of life and places patients at an increased risk for both pulmonary and nonpulmonary death. ${ }^{2-5}$

The course of COPD is characterized by exacerbations, whose frequency and severity determine much of the patients' burden from COPD. Since exacerbations impact 
both on the quality of life of patients and on their prognosis an important goal of the COPD management is to prevent exacerbations or at least reduce their severity. Long-acting bronchodilators such as long-acting $\beta_{2}$ agonists (LABA) and long-acting antimuscarinic drugs (LAMA) are central in the symptomatic management of COPD but they also prevent exacerbations by about $20 \%$. Against a backbone of LABAs or LAMAs, the addition of inhaled corticosteroids (ICS) or, more recently, phosphodiesterase-4 (PDE4) inhibitors may provide additional protection, particularly in patients with an advanced disease state. PDE4 inhibitors provide a novel approach to the treatment of COPD. These drugs exhibit a wide range of anti-inflammatory actions. Roflumilast is the only available PDE4 inhibitor and reduces airway inflammation in COPD, as assessed with sputum neutrophil and eosinophil counts. Although six randomized trials of roflumilast have been completed, ${ }^{6-9}$ the relative effect of roflumilast in addition to established interventions is not well understood.

Previous meta-analysis have relied on head-to-head randomized trials to provide evidence of relative effectiveness. ${ }^{10-16}$ Head-to-head trials provide evidence when interventions have been simultaneously compared. Other approaches, including mixed-treatment comparisons, can provide evidence of relative effects when interventions have not been evaluated directly. ${ }^{15,16}$ Two mixed-treatment meta-analyses have examined the comparative effectiveness of interventions, ${ }^{17,18}$ but did not include roflumilast. There is also controversy about the application of meta-analysis of COPD exacerbation data as original trials may report outcomes heterogeneously. ${ }^{19,20}$ The controversy debates whether one should include exacerbations rates or a binomial event occurrence whereby a patient had at least one exacerbation during the course of a randomized, controlled trial (RCT) or not.

We aimed to determine the relative effectiveness of LABA, LAMA, PDE4 inhibitors, and ICS in various combinations for a specific and clinically important endpoint, ie, exacerbations. We conducted a multiple treatment meta-analysis and multiplicative analysis to determine the relative effectiveness of these interventions.

\section{Methods}

\section{Analysis}

To overcome the controversy of whether to apply rates or binomial events (ever had an event or not), we applied both analyses. Our primary analysis was based on rates and then confirmed using the binomial analysis reported as relative risks.

\section{Eligibility criteria}

We included any published randomized clinical trial evaluating patients with moderate to severe COPD as defined by the Global Initiative on Obstructive Lung Disease (GOLD) classification, in line with the American Thoracic Society and European Respiratory Society (ATS/ERS). ${ }^{21}$ RCTs had to be of at least 24 weeks ( 6 months) duration. We considered any RCT evaluating the following therapeutic interventions: LABA (formoterol or salmeterol); LAMA (tiotropium); ICS (fluticasone or budesonide); PDE4 inhibitors (roflumilast); and combinations of these interventions. Control interventions included these active interventions or placebo. We excluded pharmacokinetic studies and proof of concept studies.

\section{Primary outcome}

The primary outcome of interest for this analysis was exacerbations rates reported in the original studies. An exacerbation is defined as "sustained worsening of the patient's condition, from the stable state and beyond normal day-to-day variations, that is acute in onset and necessitates a change in regular medication in a patient with underlying COPD". ${ }^{22}$ Where reported, we extracted data on exacerbations as moderate and severe. Moderate is considered as "patient has an increased need for medication, and he/she feels the need to seek additional medical assistance" and severe as "patient/caregiver recognizes obvious and/or rapid deterioration in condition, requiring hospitalization". ${ }^{22}$ In a sensitivity analysis, we confirmed these findings using the binomial endpoint of a patient having had at least one exacerbation event during the course of the trial.

\section{Search criteria}

Independently, in duplicate, we searched the following electronic databases (from inception to September 2010): MedLine via PubMed; EMBASE; and Cochrane CENTRAL. We used the following terms for searching, including their MeSH terms: randomized controlled trial; controlled clinical trial; randomized; chronic obstructive pulmonary disease; long-acting beta agonist (LABA); formoterol; salmeterol; long-acting muscarinic antagonists (LAMA); tiotropium; inhaled corticosteroids (ICS); fluticasone; budesonide; and roflumilast. We searched the bibliographies of relevant previous publications. Studies were restricted to those published in English. Although we read the full manuscripts of any substudies or post-hoc evaluations, our primary analyses were based on the main published study trial reports. 


\section{Data abstraction}

Two reviewers abstracted data in duplicate independently on the study characteristics, populations, and interventions. We extracted data on the primary outcome of interest, exacerbations, according to the primary definition used in each study. We extracted data on the number of exacerbations per patient arm and calculated total patient years at risk as reported in the article, or if unavailable, by the intention to treat principal by multiplying the number of participants by the planned study duration. For the binomial evaluation of rates, we extracted data on the number of patients having had at least one exacerbation in each arm over the course of the trial, regardless of how many additional exacerbations patients may have experienced.

\section{Statistical analyses}

We plotted the geometric distribution of the included trials with circles representing the interventions and lines denoting the number of trials between interventions. ${ }^{23}$ We used a mixed-treatment comparison (MTC) meta-analysis framework to analyze the data provided by the studies included in our systematic review and compare the different treatment regimens with respect to the outcomes of interest. ${ }^{24}$ This framework is suitable for meta-analytic situations where we wish to assess the relative effects of pairs of treatments based on direct and indirect evidence provided by randomized clinical trials, ${ }^{24}$ thereby providing a generalization of meta-analysis methods because it allows comparisons of agents not addressed within any of the individual primary trials. One of the advantages of this framework, from a medical decision-making viewpoint is that, when conducted in a Bayesian setting, it affords the estimation of the probability of each treatment being the best with respect to the outcome of interest. Another advantage is that this framework can accommodate study-level covariates in order to determine to what degree these covariates may help explain potential heterogeneity in the relative effects of pairs of treatments over and above that explained by chance and helps reduce the inconsistency in the network of treatments. ${ }^{25}$

Each of the studies contributed the following data to the MTC analyses conducted in this paper: i) the total number of exacerbations in COPD experienced in each treatment arm, ii) the total number of patient-years at risk per treatment arm, and iii) the total number of patients experiencing at least one exacerbation event. In order to reflect the fact that individual patients could experience multiple exacerbations in COPD over the duration of follow-up and that different trials had different durations of follow-up, we chose to model the expected rates of exacerbations in COPD per person-years. This enabled us to express the relative effects of pairs of treatments in terms of rate ratios of exacerbations in COPD.

We used the data supplied by all 26 studies to perform a primary MTC analysis, supplemented by a variety of sensitivity analyses. Our primary MTC analysis focused on comparing just the 10 interventions that were included in the 26 studies, whereas our secondary MTC analysis aimed to facilitate the comparison of all possible interventions obtained by combining the active treatments (ie, five single interventions plus 10 combinations of active single interventions). The sensitivity analyses accompanying the primary MTC analysis explored the robustness of our conclusions to changes in the nature of the data, the model or the outcome.

The primary MTC analysis used the rates of exacerbations as the outcome of interest and implemented a standard random-effects Poisson regression model that did not include any covariate, similar to the one considered by Cooper et al. ${ }^{26}$ Appendix 1 provides a description of the model implementation of our primary analysis along with details concerning its WinBUGS implementation (MRC Biostatistics Unit, Cambridge, UK).

The sensitivity analyses accompanying our primary MTC analyses proceeded along the following lines. First, we examined a fixed-effects Poisson regression model; second, we applied a random-effects logistic regression model to the binomial event rates using relative risk as the pooled effect size, and third, we examined i) whether or not covariates such as severity of COPD exacerbations and study publication year could be used to explain the between-study heterogeneity in our primary MTC analysis, and ii) whether the results produced by the primary MTC analysis were insensitive to various choices of Bayesian priors for the between-study standard deviation. We also re-run our primary analysis using the same data as for the secondary analysis. In the secondary analysis, the data for one of the published trials by Calverley was replaced with that from a trial unpublished at the time of manuscript acceptance that pooled the Calverley trial with new data. ${ }^{27}$ Appendix 1 displays the results of the main sensitivity analyses.

While our primary MTC analysis enabled us to derive the relative effects of the interventions directly investigated in the 26 studies included in our systematic review, it did not afford enough flexibility to facilitate comparisons between combinations of active treatments not investigated in these studies. For instance, given that roflumilast plus LABA was directly investigated in one of the 26 studies and LABA plus LAMA was directly investigated in two of the 26 studies, 
the relative effect of roflumilast plus LABA versus LABA plus LAMA could easily be derived on the basis of the primary MTC analysis. Nevertheless, this analysis did not support the derivation of the relative effect of roflumilast plus LABA plus LAMA versus LABA plus LAMA, as none of the 26 studies utilized in the analysis investigated the effect of roflumilast plus LABA plus LAMA relative to that of another intervention.

To overcome this limitation of our primary MTC analysis, we conducted a secondary MTC analysis. Just like the primary MTC analysis, the secondary MTC analysis used the rates of exacerbations as the outcome of interest and relied on a random-effects Poisson regression model for the intervention effects. In this model, termed an additive main-effects model, each of the single treatments of placebo, roflumilast, LABA, LAMA, and ICS was allowed to have a different mean effect, denoted by $d_{\text {Placebo }}, d_{\text {Roflumilast }}, d_{L A B A}, d_{L A M A}$, and $d_{I C S}$, respectively. Furthermore, the effect of each combination of two or more active treatments (eg, roflumilast plus LABA plus LAMA), was expressed as a sum of the relevant active component effects, $d_{\text {Roflumilast }}, d_{L A B A}, d_{L A M A}$, and $d_{I C S}$, for a particular intervention $k$. So for the intervention roflumilast plus LABA plus LAMA, one had $d_{k}=d_{\text {Roflumilast }}+d_{L A B A}+d_{L A M A}$. More generally, for the intervention $k$, one had:

$$
\begin{aligned}
d_{k}= & d_{\text {Roflumilast }} * I_{k \supset \text { Roflumilast }}+d_{L A B A} * I_{k \supset L A B A} \\
& +d_{\text {LAMA }} * I_{k \supset L A M A}+d_{I C S} * I_{k \supset I C S},
\end{aligned}
$$

where the notation $d_{\text {Roflumilast }} * I_{k \supset \text { Roflumilast }}$ means that the intervention $k$ included a roflumilast component. (In other words, $I_{k \supset \text { Roflumilast }}$ was set to 1 if $d_{k}$ included a roflumilast component and 0 otherwise). Our additive main effects model is similar to the additive main effects models considered by Welton et $\mathrm{al}^{28}$ with the difference being that we used rates of exacerbation as our outcome, rather than binary or continuous outcomes.

Our primary and secondary MTC analyses assumed that 1) the study-specific relative treatment effects were different yet similar enough to combine from a common population and 2) the potential heterogeneity in study-specific relative treatment effects was constant across pairwise treatment comparisons. Various sensitivity analysis models additionally assumed that potential heterogeneity in study-specific relative treatment effects could not be explained by chance alone and investigated to what extent a study-specific covariate would help explain the excess between-study variation. These models assumed that the effect of the covariate of interest on the relative effects of pairs of treatments was common across all pairwise treatment comparisons. All models took into account the correlation structure induced by the multi-arm trials, except for the random-effects logistic regression model used in the sensitivity analysis relying on binomial event rates.

For both the primary and secondary MTC analyses, we produced estimated rate ratios of exacerbations in COPD per patient-years and corresponding 95\% confidence intervals for each pairwise treatment comparison. We also produced estimates of the absolute effect of each treatment - expressed as mean exacerbations per patient-years - as well as estimated probabilities that each treatment is best (in the sense of being associated with the lowest rate of exacerbations in COPD per patient-years).

We produced similar quantities for the sensitivity analyses utilizing the rates of exacerbations as an outcome. For the sensitivity analyses involving binomial event rates, we produced estimated relative risks and corresponding 95\% confidence intervals for each pairwise treatment comparison, along with estimates of the absolute effect of each treatment and estimated probabilities that each treatment is best.

For all MTC analyses, we measured the goodness of fit of each of the models to the data by calculating the residual deviance and comparing it against the number of unconstrained data points, where the number of unconstrained data points was obtained by summing up the number of study arms across all studies included in our analyses. Given a model, the residual deviance is defined as the difference between the deviance for the fitted model and the deviance for the saturated model, where the deviance measures the fit of the model to the unconstrained data points using the appropriate likelihood function (eg, Poisson likelihood, binomial likelihood). Under the null hypothesis that the model provides an adequate fit to the data, the residual deviance is expected to have a mean equal to the number of unconstrained data points. ${ }^{26}$ We compared the fits of the models using the deviance information criterion (DIC). A model with its DIC being at least three points lower than a second model is considered to have a better fit. ${ }^{29}$

We fitted all models via a Bayesian Markov chain Monte Carlo (MCMC) method, as implemented in the freely available software WinBUGS (Version 1.4; MRC Biostatistics Unit). Given each model, we used noninformative normal priors for all model parameters except for the between-study standard deviation, for which we used an noninformative uniform prior (range 0-10). For each model, we ran two MCMC chains for 100,000 iterations with a thin parameter of 10 after a 'burn-in' of 20,000 in order to ensure convergence of the MCMC sampler. We conducted posterior inference after discarding the 'burn-in' iterations, thereby relying on 20,000 samples. The results of the model fits are also presented in 
Appendix 1. We checked the MTC rate outcomes to standard pairwise random-effects meta-analysis for consistency. ${ }^{30}$

\section{Results Inclusion of studies}

Twenty-six studies met our inclusion criteria for our primary analysis. ${ }^{6-9,31-54}$ Of the four studies each reporting on two clinical trials, three pooled the trial data together, ${ }^{6,34,39}$ and one reported each trial separately. ${ }^{7}$

Thirty clinical trials included in two previous metaanalyses assessing COPD drugs ${ }^{17,55}$ were excluded from our study because they did not meet our inclusion criteria. ${ }^{56-83}$ Eighteen of these clinical trials were excluded because the treatment duration was less than 24 weeks in length. ${ }^{56,59,60,62-65,67,69,70,72,74,75,77,79-82}$ Eleven were excluded because they assessed treatments that were not of interest, ${ }^{57,61,66,76,83}$ they did not provide sufficient detail on exacerbations, ${ }^{54,68,71,73}$ they were published in a language other than English, ${ }^{58}$ or they examined the effect of drug discontinuation. ${ }^{78}$ One additional clinical trial ${ }^{84}$ included in the previous meta-analyses was excluded from our study because the data was later republished together with another trial. ${ }^{34}$ We considered the data from both trials as published in the second manuscript. ${ }^{34}$ Five clinical trials found in our comparable search were also excluded because they did not provide sufficient detail on exacerbations ${ }^{2-4}$ or the treatment duration was less than 24 weeks in length., ${ }^{5,10}$ Figure 1 displays the study flow diagram.

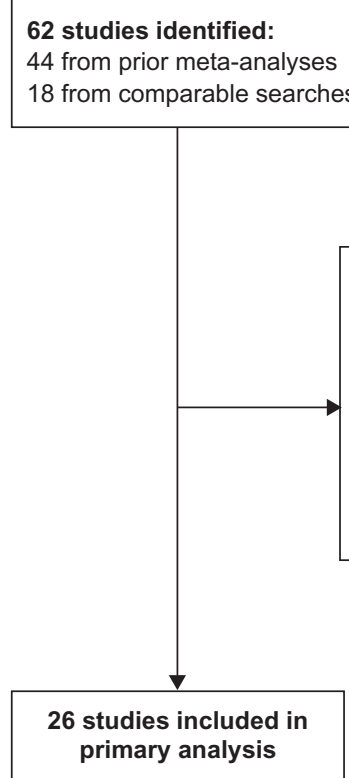

Figure I Flow diagram of included studies.
All clinical trials that met our inclusion criteria reported COPD exacerbations following treatment. All clinical trials recruited patients with a forced expiratory volume in 1 second $\left(\mathrm{FEV}_{1}\right)<80 \%$ of the predicted value. Duration of treatment ranged from 24 weeks to 4 years. All clinical trials permitted the use of background therapy and/or rescue therapy. Twenty of the randomized trials used a placebo control, ${ }^{6,8,9,33-42,45-51,54} 12$ assessed LAMA, $7,31,34,39,40,42,45,47,50-53$ 13 assessed LABA, $7,32,34,36-38,41,43,44,48,49,52,547$ assessed ICS, ${ }^{33,35-38,48,49} 3$ assessed roflumilast, ${ }^{6,8,9}$ and 13 assessed combinations of these drugs: 2 LAMA plus LABA, ${ }^{31,52} 8$ LABA plus ICS, ${ }^{32,36-38,43,44,49,53} 1$ LAMA plus LABA plus ICS, ${ }^{31}$ 1 LAMA plus roflumilast, ${ }^{7}$ and 1 LABA plus roflumilast. ${ }^{7}$

Twenty-six studies provided data on the total number of exacerbations and/or the mean annual rate of exacerbations among a combined 36,312 patients..$^{6-9,31,32,34-40,42-51,53,54}$ These data contributed to our first analysis of total exacerbations. Table 1A provides the characteristics of these clinical trials. An additional three studies ${ }^{33,41,52}$ provided data on the proportion of patients with at least one exacerbation allowing a combined 36,657 patients. These data contributed to our second analysis of the number of patients with at least one exacerbation. Table 1B provides the characteristics of these clinical trials.

The network of treatments compared is displayed in Figure 2. The treatments form a closed network, which is amenable to MTC analyses.

\section{Reporting quality}

We assessed the quality of reporting specific methodological items. Eighteen reported on how randomization was achieved, ${ }^{6-9,31-33,35,36,38,41,43,45,46,48,50,51,53} 16$ reported on concealment of allocation, ${ }^{6-9,31-33,35,36,38,44} 46,48,50,5314$ reported on blinding, ${ }^{6-9,31,33,35,36,38,40,45,46,50,54} 20$ were assumed as intentionto-treat time periods, ${ }^{6-9,32,33,34,36-42,45,46,48,49,52,53}$ and 20 had greater than $20 \%$ drop-outs. ${ }^{6,9,31,32,35-40,42,43,45,47-51,53,54}$

\section{Results of the primary MTC analysis}

The random-effects Poisson regression model considered in our primary MTC analysis provides a reasonable fit to the data, as evidenced by the low residual deviance (67.61) compared to the unconstrained number of data points (62).

Table 2 reports the estimated rate ratios of exacerbations and $95 \%$ confidence intervals for the relative effects of the 10 interventions for management of COPD investigated in the 26 studies. Figure 3 displays these results graphically. As can be seen from Table 2 and the direct (head-to-head) evaluations reported in Appendix 1 (Tables 7 and 8), the studies provide consistent results. 


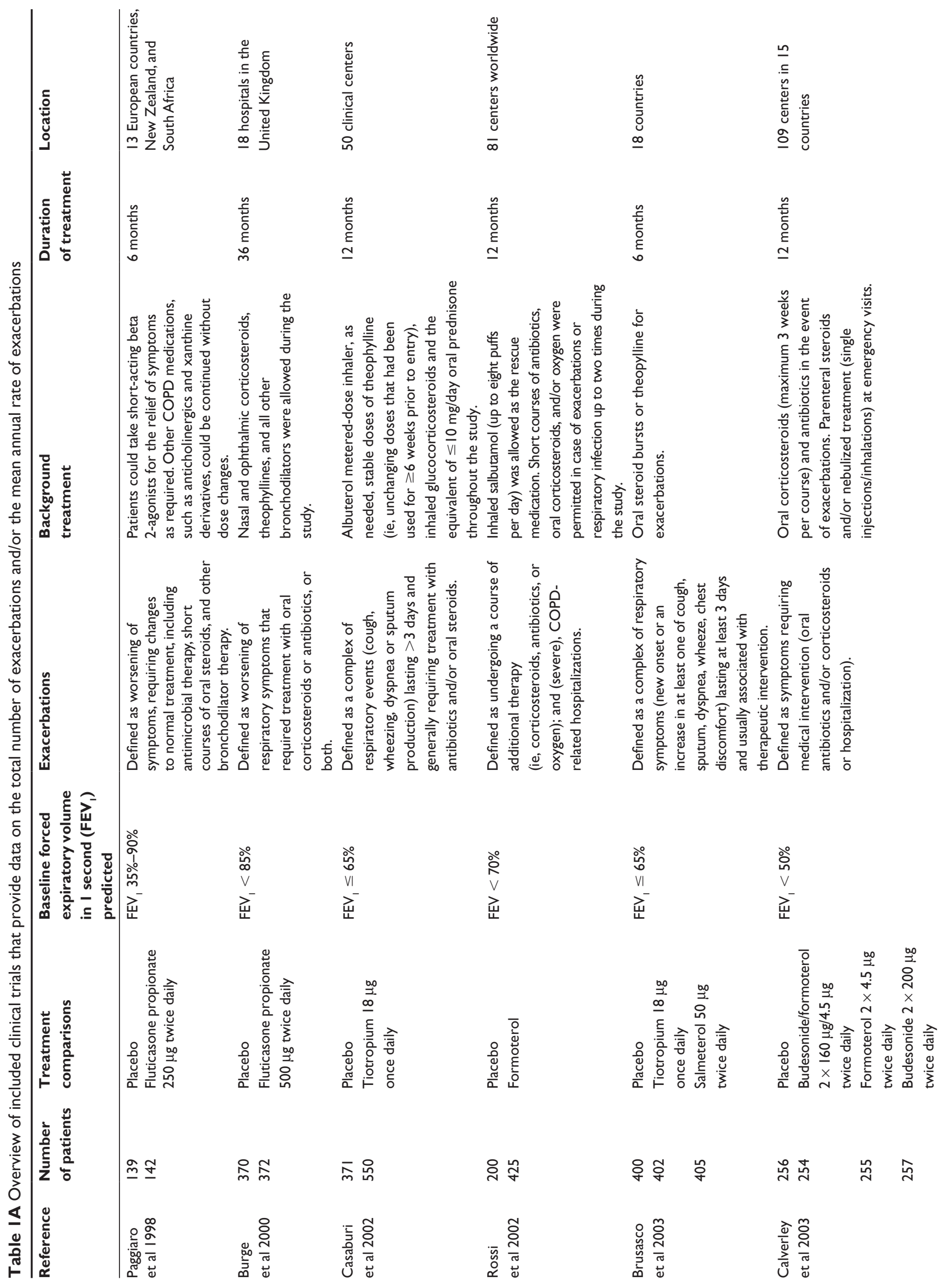



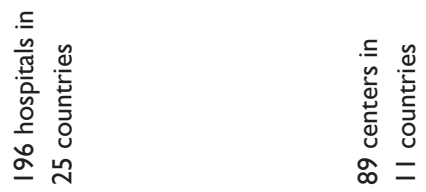

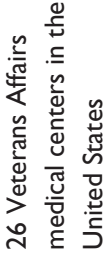

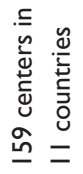

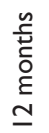

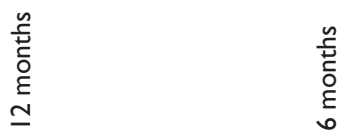

$\stackrel{n}{+}$
$\stackrel{0}{0}$
0
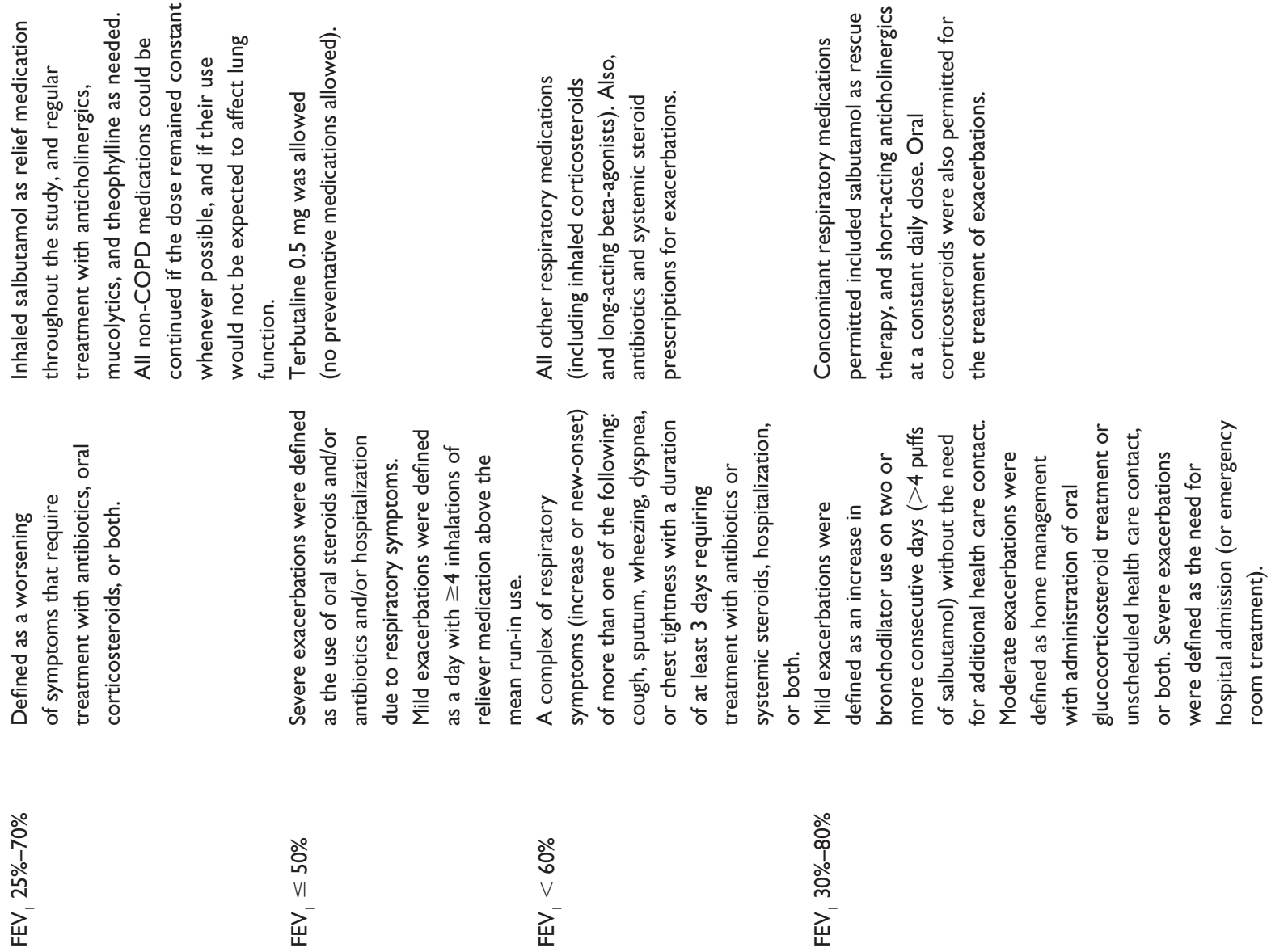

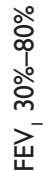
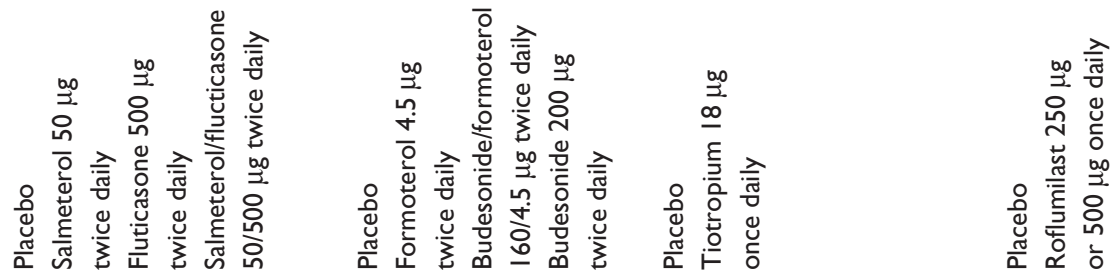

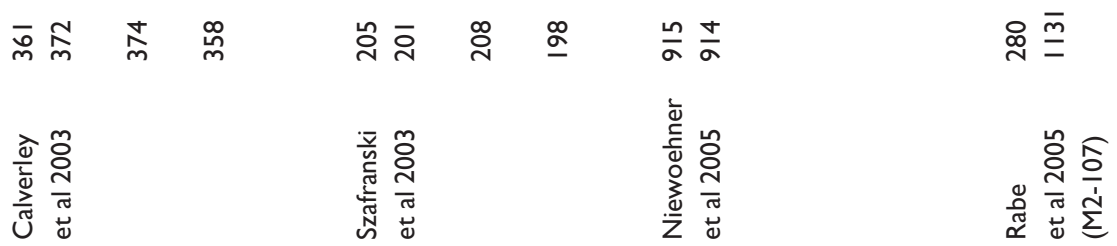




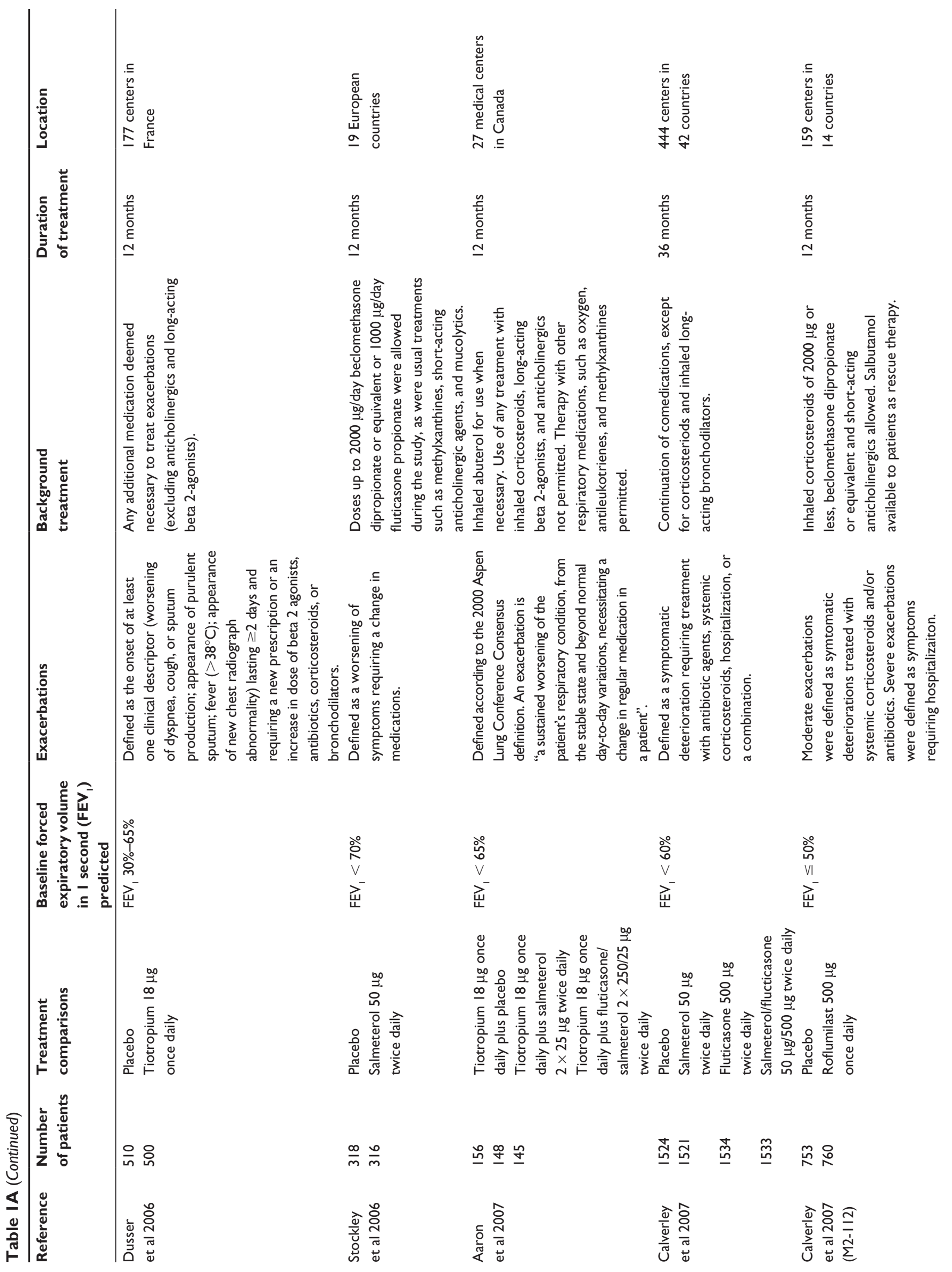




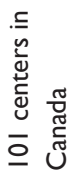

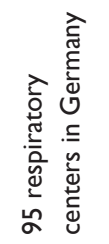

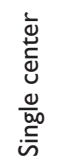
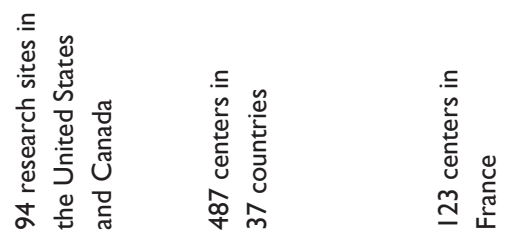

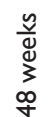

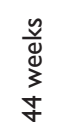

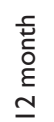

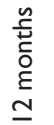

$\stackrel{n}{+}$
$\stackrel{+}{0}$
$\stackrel{5}{\xi}$
$\stackrel{+}{+}$

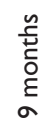
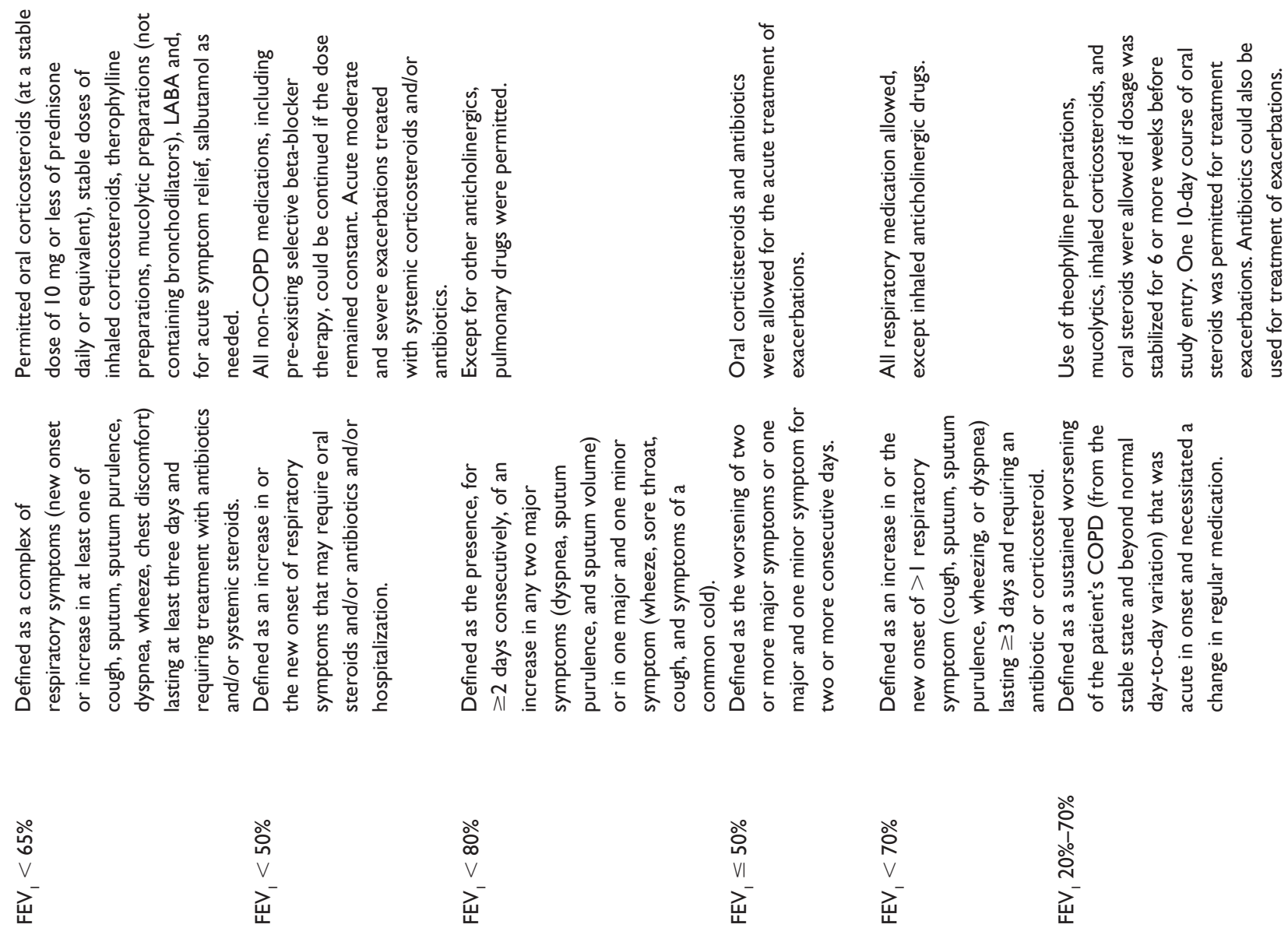

$\stackrel{\circ}{\infty}$
$\vee$
$\stackrel{-}{\Psi}$

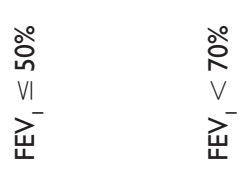

ฏ̊ำ
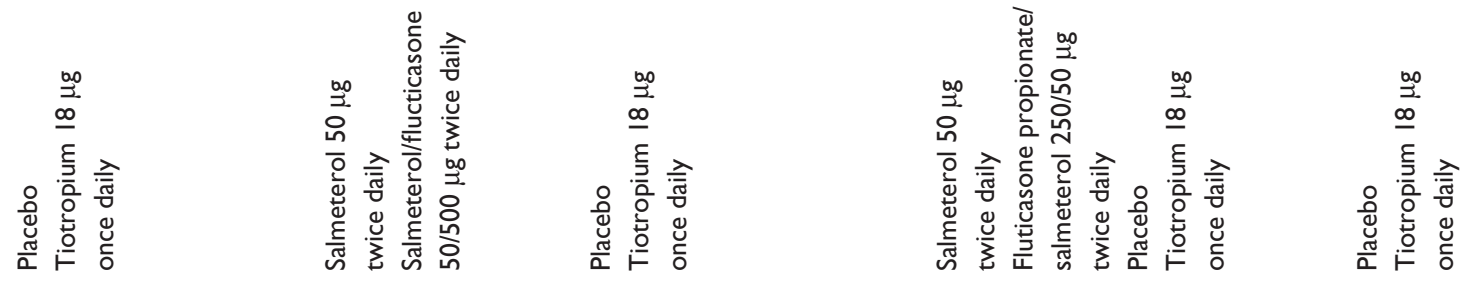

ㄴํํ :

कo

ต

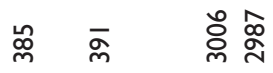

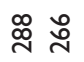

立先

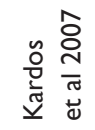

을

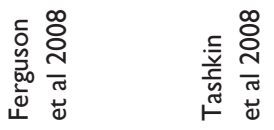

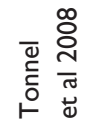




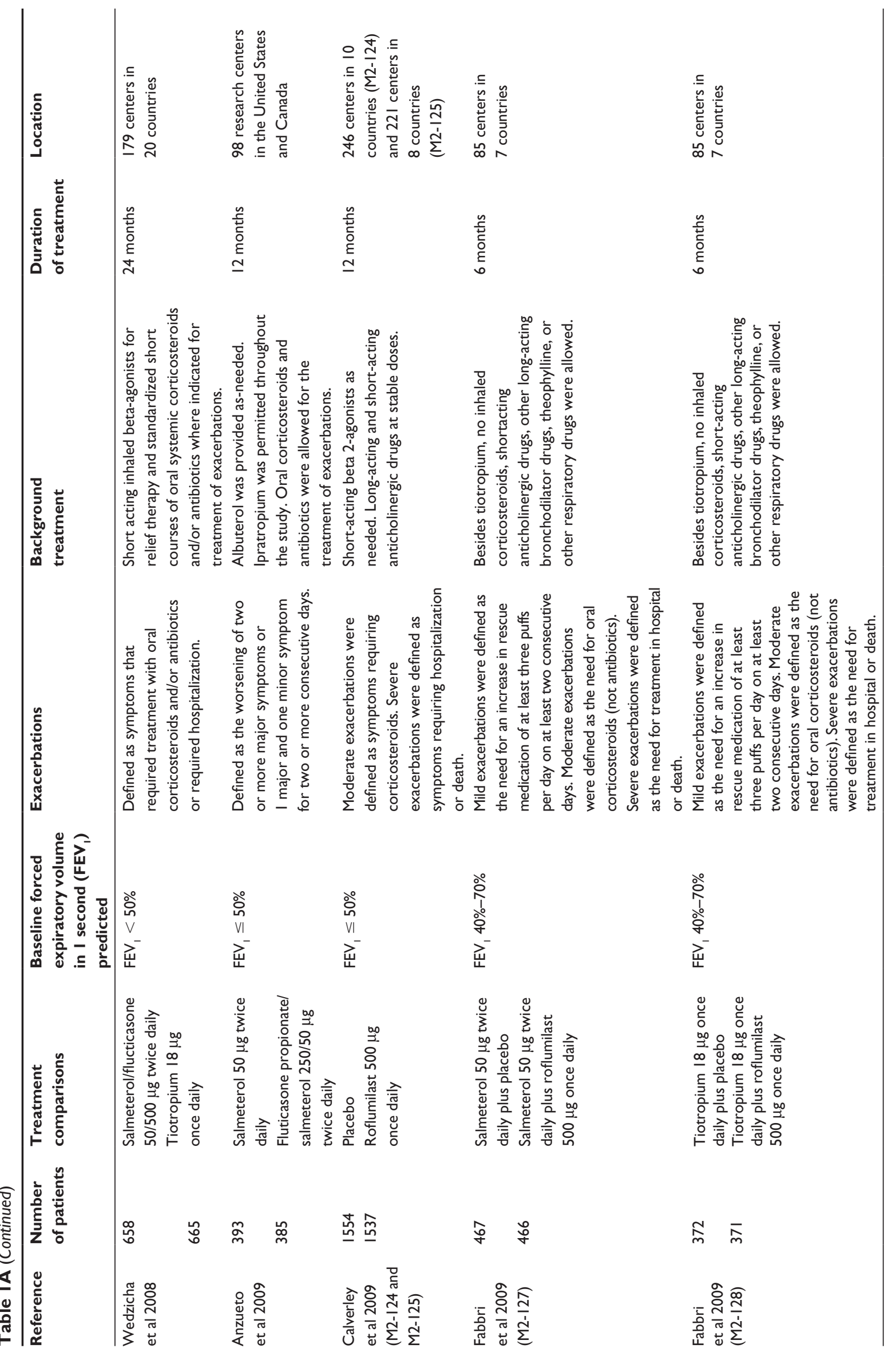




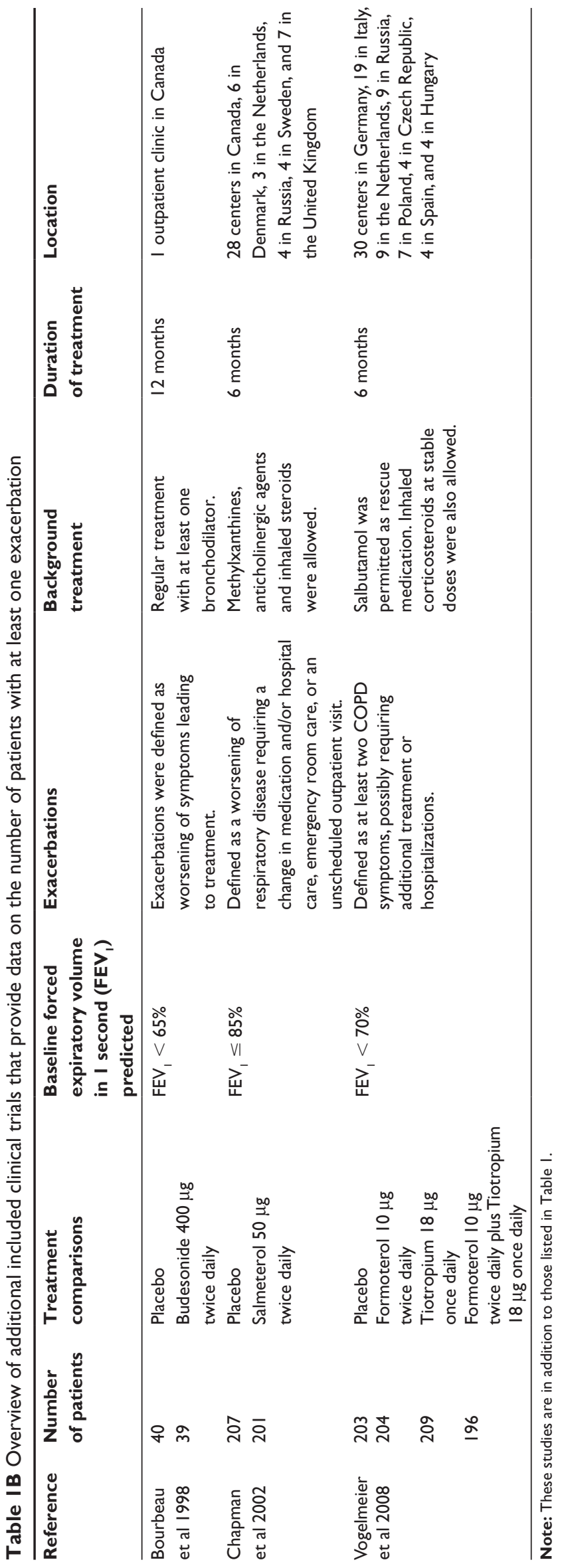

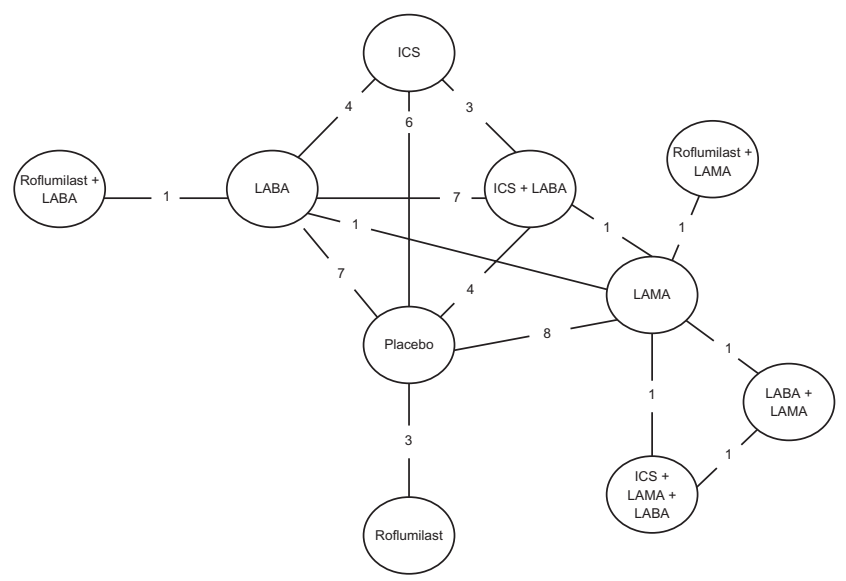

Figure 2 Diagram displaying the network of 10 treatments involved in the MTC analyses of the COPD data. Each treatment is a node in the network. The links between nodes are used to indicate a direct comparison between pairs of treatments. The numbers shown along the link lines indicate the number of trials comparing pairs of treatments head-to-head.

Abbreviations: COPD, chronic obstructive pulmonary disease; ICS, inhaled corticosteroids; LABA, long-acting beta agonists; LAMA, long-acting antimuscarinic drugs; MTC, mixed-treatment comparison.

Table 3 reports the absolute treatment effects corresponding to the 10 interventions, expressed as mean exacerbations per patient-years. The findings in this table favor both current intensive therapy (ICS plus LABA plus LAMA) and also the addition of roflumilast to this therapy.

Table 4 reports the probability that each treatment is best obtained on the basis of our primary analysis. Each column represents the possibility of first-line treatment, second-line, and so on. According to Table 4, the highest probability of reductions in exacerbations is found from the combination of roflumilast plus a LAMA.

\section{Results of the additive MTC analysis}

Our additive main effects model considered in our secondary MTC analysis provides adequate fit to the data, as evidenced by the low residual deviance (69.56) compared to the unconstrained number of data points (62) (slightly lower than that of the model considered in our primary MTC analysis, but still within a 3-point difference), suggesting that this model is comparable to the one used in our primary MTC analysis.

Table 5 reports the estimated rate ratios of exacerbations and $95 \%$ confidence intervals for the relative effects of specific pairs of treatment combinations. Each pair is of the form "comparator plus roflumilast" vs "comparator", with "comparator" being one of the combinations LABA plus ICS, LABA plus ICS plus LAMA, and LABA plus LAMA.

Table 6 reports the absolute treatment effects corresponding to the 15 interventions (ie, 5 single treatments plus 10 
Table 2 Estimated rate ratios and $95 \% \mathrm{Cl}$ for the relative effects of pairs of treatments, produced by the random-effects MTC model without covariates

\begin{tabular}{|c|c|c|}
\hline \multirow[t]{2}{*}{ Treatment vs comparator } & \multicolumn{2}{|c|}{$\begin{array}{l}\text { Random-effects MTC } \\
\text { model }\end{array}$} \\
\hline & Rate ratio & $95 \% \mathrm{Cl}$ \\
\hline Roflumilast vs placebo & 0.85 & $(0.72,0.97)$ \\
\hline LABA vs placebo & 0.84 & $(0.75,0.93)$ \\
\hline LAMA vs placebo & 0.74 & $(0.66,0.81)$ \\
\hline ICS vs placebo & 0.80 & $(0.7 \mathrm{I}, 0.90)$ \\
\hline Roflumilast + LABA vs placebo & 0.67 & $(0.48,0.91)$ \\
\hline Roflumilast + LAMA vs placebo & 0.62 & $(0.44,0.85)$ \\
\hline LABA + LAMA vs placebo & 0.80 & $(0.56, I .12)$ \\
\hline ICS + LABA vs placebo & 0.69 & $(0.61,0.77)$ \\
\hline ICS + LAMA + LABA vs placebo & 0.68 & $(0.47,0.95)$ \\
\hline LABA vs roflumilast & 0.98 & $(0.80,1.19)$ \\
\hline LAMA vs roflumilast & 0.87 & $(0.7 I, I .05)$ \\
\hline ICS vs roflumilast & 0.94 & $(0.76,1.15)$ \\
\hline Roflumilast + LABA vs roflumilast & 0.79 & $(0.54,1.12)$ \\
\hline Roflumilast + LAMA vs roflumilast & 0.73 & $(0.50,1.04)$ \\
\hline LABA + LAMA vs roflumilast & 0.94 & $(0.63, I .36)$ \\
\hline ICS + LABA vs roflumilast & 0.81 & $(0.66,0.99)$ \\
\hline ICS + LAMA + LABA vs roflumilast & 0.80 & $(0.53,1.16)$ \\
\hline LAMA vs LABA & 0.88 & $(0.77,1.01)$ \\
\hline ICS vs LABA & 0.96 & $(0.84,1.09)$ \\
\hline Roflumilast + LABA vs LABA & 0.80 & $(0.59,1.08)$ \\
\hline Roflumilast + LAMA vs LABA & 0.75 & $(0.52,1.03)$ \\
\hline LABA + LAMA vs LABA & 0.96 & $(0.66,1.35)$ \\
\hline ICS + LABA vs LABA & 0.82 & $(0.74,0.92)$ \\
\hline ICS + LAMA + LABA vs LABA & 0.82 & $(0.56,1.15)$ \\
\hline ICS vs LAMA & 1.09 & $(0.93,1.26)$ \\
\hline Roflumilast + LABA vs LAMA & 0.91 & $(0.64,1.25)$ \\
\hline Roflumilast + LAMA vs LAMA & 0.84 & $(0.61,1.14)$ \\
\hline LABA + LAMA vs LAMA & 1.09 & $(0.77,1.49)$ \\
\hline ICS + LABA vs LAMA & 0.94 & $(0.8 \mathrm{I}, \mathrm{I} .07)$ \\
\hline ICS + LAMA + LABA vs LAMA & 0.92 & $(0.66,1.28)$ \\
\hline Roflumilast + LABA vs ICS & 0.84 & $(0.60,1.15)$ \\
\hline Roflumilast + LAMA vs ICS & 0.78 & $(0.54,1.08)$ \\
\hline LABA + LAMA vs ICS & 1.01 & $(0.69,1.42)$ \\
\hline ICS + LABA vs ICS & 0.86 & $(0.76,0.98)$ \\
\hline ICS + LAMA + LABA vs ICS & 0.86 & $(0.58,1.21)$ \\
\hline Roflumilast + LAMA vs roflumilast + LABA & 0.95 & $(0.58,1.46)$ \\
\hline LABA + LAMA vs roflumilast + LABA & 1.23 & $(0.74,1.90)$ \\
\hline ICS + LABA vs roflumilast + LABA & 1.05 & $(0.75,1.43)$ \\
\hline LAMA + ICS + LABA vs roflumilast + LABA & 1.04 & $(0.63,1.63)$ \\
\hline LABA + LAMA vs roflumilast + LAMA & 1.32 & $(0.82,2.03)$ \\
\hline ICS + LABA vs roflumilast + LAMA & 1.14 & $(0.80,1.58)$ \\
\hline ICS + LAMA + LABA vs roflumilast + LAMA & 1.12 & $(0.70,1.72)$ \\
\hline ICS + LABA vs LABA + LAMA & 0.88 & $(0.61,1.24)$ \\
\hline ICS + LAMA + LABA vs LABA + LAMA & 0.86 & $(0.61,1.18)$ \\
\hline ICS + LAMA + LABA vs ICS + LABA & 0.99 & $(0.68,1.40)$ \\
\hline
\end{tabular}

Notes: A rate ratio smaller (larger) than I indicates that the treatment is associated with a reduction (increase) in the rate of exacerbations in COPD relative to the comparator. This reduction (increase) is statistically significant at the $5 \%$ level only if the upper end (lower end) of the associated $95 \% \mathrm{Cl}$ is less than (larger than) I. Abbreviations: $\mathrm{Cl}$, confidence interval; COPD, chronic obstructive pulmonary disease; ICS, inhaled corticosteroids; LABA, long-acting beta agonists; LAMA, long-acting antimuscarinic drugs; MTC, mixed-treatment comparison. combinations of active treatments), expressed as mean exacerbations per patient-years. The findings in this table favor both current intensive therapy (ICS plus LABA plus LAMA) and also the addition of roflumilast to this therapy (roflumilast plus ICS plus LABA plus LAMA).

Table 7 reports the probability that each treatment is best, obtained on the basis of our secondary analysis. The highest probability of reductions in exacerbations is found from the combination of roflumilast and the current intensive therapy (roflumilast plus ICS plus LABA plus LAMA). All data and output from this model are available from the authors upon request.

\section{Results of the sensitivity analyses}

Our first sensitivity analysis replaced the random-effects Poisson regression model used in the primary MTC analysis with a fixed-effect Poisson regression model. The results of this sensitivity analysis can be found in Appendix 1 (Appendix Tables 1-3). In particular, these results suggest that the fixed-effect and random-effects analyses provide consistent finding. However, the residual deviance associated with the model employed in the fixed-effect analysis is considerably higher (189.00) than that associated with the model used in the random-effects analysis, indicating that the fixed effects model provides a questionable fit to the data.

Appendix Tables 4-6 and 8 present the findings of our second sensitivity analysis examining the binomial event of ever having an exacerbation event within the intention to treat population over the study period. We found consistent effects between the primary MTC analysis using rates of exacerbation and the current sensitivity analysis using binomial outcomes. This strengthens the inference about the credibility of the analysis and the relative treatment effects of the interventions. Appendix Table 6 provides similar probabilities that each treatment is best as first line therapy. The results of the sensitivity analyses examining the inclusion of previously unpublished roflumilast data (M-111 trial) ${ }^{27}$ are presented in Appendix Tables 9-12.

The results of the remaining sensitivity analyses are omitted in the interest of saving space. These analyses found that the choice of prior for the between-study standard deviation did not influence the outcome of our primary MTC analysis. Also, disease severity and study publication year were found to be insignificant modifiers of the relative treatment effects produced by the random-effects Poisson regression model. This data is available from the authors upon request. 


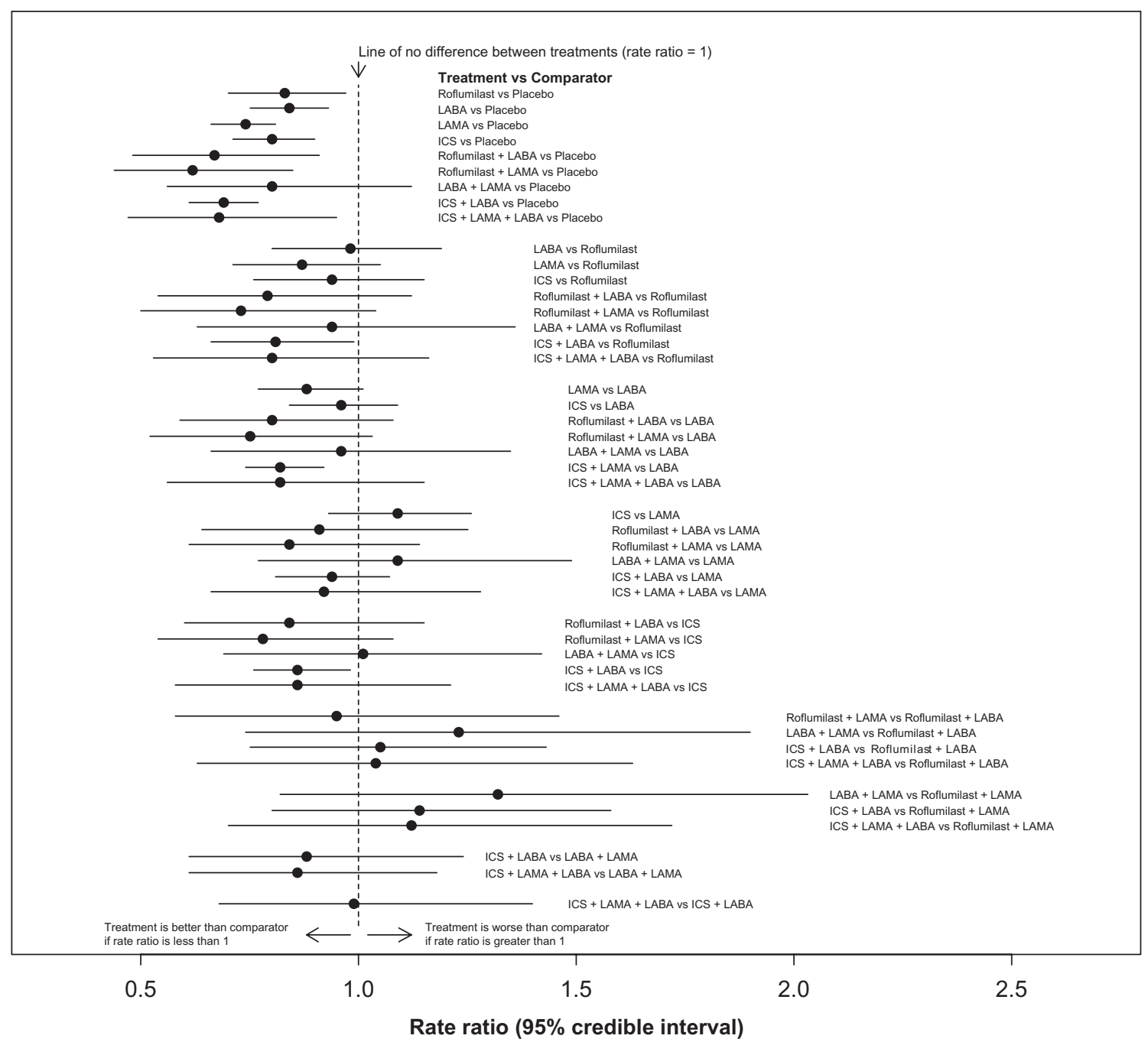

Figure 3 Comparisons of all 10 different treatments for management of COPD. Rate ratios and associated $95 \%$ confidence intervals were obtained from a random-effects MTC model without covariates.

Abbreviations: COPD, chronic obstructive pulmonary disease; ICS, inhaled corticosteroids; LABA, long-acting beta agonists; LAMA, long-acting antimuscarinic drugs; MTC, mixed-treatment comparison.

Table 3 Absolute treatment effects corresponding to the 10 treatments for the management of COPD as derived from the primary analysis

\begin{tabular}{lll}
\hline Treatment & Absolute treatment effect & $\mathbf{9 5 \%} \mathbf{~ C l}$ \\
\hline Placebo & 1.21 & $(I .17, I .24)$ \\
Roflumilast & 1.03 & $(0.87, I .21)$ \\
LABA & 1.01 & $(0.90,1.1 \mathrm{I})$ \\
LAMA & 0.89 & $(0.80,0.98)$ \\
ICS & 0.96 & $(0.85,1.08)$ \\
Roflumilast + LABA & 0.81 & $(0.58,1.10)$ \\
Roflumilast + LAMA & 0.75 & $(0.53,1.02)$ \\
LABA + LAMA & 0.97 & $(0.67,1.34)$ \\
ICS + LABA & 0.83 & $(0.73,0.93)$ \\
ICS + LAMA + LABA & 0.82 & $(0.57,1.15)$ \\
\hline
\end{tabular}

Note: Absolute treatment effects are expressed as mean exacerbations experienced per patient per patient-year.

Abbreviations: COPD, chronic obstructive pulmonary disease; ICS, inhaled corticosteroids; LABA, long-acting beta agonists; LAMA, long-acting antimuscarinic drugs; MTC, mixed-treatment comparison.

\section{Discussion}

Our study demonstrates that there are small differing treatment effects according to the choice of treatment combinations chosen. In our analysis, combinations treatments demonstrated the largest probability of the largest therapeutic effects. Using an additive main effects analysis, whereby we create combinations that have not been compared together in the trials, we demonstrate that new combinations that include roflumilast appear to offer comparable treatment options to reduce the risk for exacerbations.

To our knowledge, our analysis is the most up to date analysis of interventions recommended in the GOLD and ATS/ERS guidelines for the treatment of COPD. ${ }^{21}$ There are, of course, other treatments used in COPD, ranging from behavioral therapies to other pharmacotherapies. As with any 
Table 4 Probability each of the 10 treatments for management of COPD is best, obtained on the basis of the random-effects MTC model without covariates

\begin{tabular}{|c|c|c|c|c|c|c|c|c|c|c|}
\hline Treatment & $\mathbf{P}^{*} \mathbf{I}$ & $\mathbf{P 2}$ & P3 & P4 & P5 & P6 & P7 & P8 & P9 & PIO \\
\hline Placebo & 0.000 & 0.000 & 0.000 & 0.000 & 0.000 & 0.000 & 0.001 & 0.012 & 0.113 & 0.875 \\
\hline Roflumilast & 0.001 & 0.004 & 0.010 & 0.026 & 0.052 & 0.103 & 0.168 & 0.238 & 0.372 & 0.027 \\
\hline LABA & 0.000 & 0.000 & 0.002 & 0.008 & 0.040 & 0.117 & 0.259 & 0.354 & 0.218 & 0.001 \\
\hline LAMA & 0.001 & 0.026 & 0.110 & 0.272 & 0.332 & 0.199 & 0.048 & 0.010 & 0.002 & 0.000 \\
\hline ICS & 0.001 & 0.004 & 0.019 & 0.060 & 0.139 & 0.246 & 0.308 & 0.165 & 0.059 & 0.000 \\
\hline Roflumilast + LABA & 0.244 & 0.231 & 0.155 & 0.114 & 0.082 & 0.069 & 0.042 & 0.032 & 0.024 & 0.007 \\
\hline Roflumilast + LAMA & 0.453 & 0.224 & 0.130 & 0.071 & 0.045 & 0.032 & 0.018 & 0.015 & 0.010 & 0.002 \\
\hline LABA + LAMA & 0.025 & 0.066 & 0.096 & 0.096 & 0.104 & 0.129 & 0.102 & 0.124 & 0.178 & 0.081 \\
\hline ICS + LABA & 0.056 & 0.218 & 0.322 & 0.238 & 0.121 & 0.041 & 0.004 & 0.000 & 0.000 & 0.000 \\
\hline ICS + LAMA + LABA & 0.219 & 0.226 & 0.157 & 0.115 & 0.086 & 0.065 & 0.049 & 0.050 & 0.026 & 0.008 \\
\hline
\end{tabular}

Note: $\mathrm{PI}-\mathrm{PIO}$ refers to probability that each is Ist, $2 \mathrm{nd}, \ldots, k$ best.

Abbreviations: COPD, chronic obstructive pulmonary disease; ICS, inhaled corticosteroids; LABA, long-acting beta agonists; LAMA, long-acting antimuscarinic drugs; MTC, mixed-treatment comparison.

research study, we set out our study questions, interventions of interest and populations a priori. We believe that our study findings should be of relevance to physicians working with pharmacotherapies and any recommendations for treatment should go hand in hand with individual patient advice tailored to the patient's situation.

Our findings represent an update of two previously published mixed treatment comparisons. ${ }^{17,55}$ Our findings are similar to these previous reviews, but differ in two important ways. First, neither review included PDE4 inhibitors, the interventions that appeared most favorable in our analysis. Second, both reviews examined exacerbations as a binomial outcome of whether a patient ever had an exacerbation or not. This outcome is problematic depending on the study population. For example, to take an extreme example, in a population enrolling very severe patients we would expect all patients to have at least one exacerbation, thus the study would find no treatment effect even if the trial intervention importance reduced the frequency of exacerbations.

As with any analysis, there are limitations to consider when interpreting our analysis. We combined exacerbation events across trials that may have differed in terms of patient populations, exacerbation definitions, and study design features. Indeed, this issue applies to all meta-analyses and we considered a priori whether it was appropriate to pool trials and considered it appropriate. ${ }^{85}$ Despite the large number of patients included in the trials, power to differentiate across interventions is potentially an issue. Indirect comparisons typically require four times the amount of data as a direct comparison and in our analysis we had several comparisons that had only one trial in them. Thus, it is possible that we were unable to identify significant effects where they may exist. The MTC approach aims to borrow power from other studies that use comparable interventions in their study arms, regardless of whether the data from all treatment arms can be utilized. ${ }^{86}$ We searched thoroughly for relevant clinical trials to include, but it is possible we have missed unpublished studies. Strengths of our study include our extensive analysis that examined the impact of differing strategies of analysis on the final outcomes. Our sensitivity analyses examined both time period of publication and severity of patients and found similar treatment effects regardless of these issues.

Table 5 Estimated rate ratios and $95 \% \mathrm{Cl}$ for the effects of specific pairs of treatment combinations, produced by the additive main effects model considered in our secondary MTC analysis

\begin{tabular}{lll}
\hline Treatment vs comparator & \multicolumn{2}{l}{ Additive main effects model } \\
\cline { 2 - 3 } & Rate ratio & $\mathbf{9 5 \%} \mathbf{C l}$ \\
\hline LABA plus ICS plus roflumilast vs LABA plus ICS & 0.84 & $(0.74,0.95)$ \\
LABA plus ICS plus LAMA vs LABA plus ICS plus roflumilast & 0.89 & $(0.75,1.03)$ \\
LABA plus ICS plus LAMA plus roflumilast vs LABA plus ICS plus LAMA & 0.84 & $(0.74,0.95)$ \\
LAMA plus LABA plus roflumilast vs LABA plus LAMA & 0.84 & $(0.74,0.95)$ \\
LAMA plus LABA plus roflumilast vs LAMA plus LABA plus ICS & 1.00 & $(0.85,1.13)$ \\
\hline
\end{tabular}

Notes: A rate ratio smaller (larger) than I indicates that the treatment is associated with a reduction (increase) in the rate of exacerbations in COPD relative to the comparator. This reduction (increase) is statistically significant at the $5 \%$ level only if the upper end (lower end) of the associated $95 \% \mathrm{Cl}$ is less than (larger than) I.

Abbreviations: COPD, chronic obstructive pulmonary disease; ICS, inhaled corticosteroids; LABA, long-acting beta agonists; LAMA, long-acting antimuscarinic drugs; MTC, mixed-treatment comparison. 
Table 6 Absolute treatment effects corresponding to the 15 treatments for the management of COPD (ie, 5 single treatments plus 10 combinations of active treatments), obtained on the basis of the additive main effects model considered in our secondary MTC analysis

\begin{tabular}{|c|c|c|}
\hline Treatment & $\begin{array}{l}\text { Absolute } \\
\text { treatment effect }\end{array}$ & $95 \% \mathrm{Cl}$ \\
\hline Placebo & 1.20 & $(1.17,1.23)$ \\
\hline Roflumilast & 1.01 & $(0.89,1.14)$ \\
\hline LABA & 1.04 & $(0.96,1.12)$ \\
\hline LAMA & 0.89 & $(0.8 \mathrm{I}, 0.98)$ \\
\hline ICS & 0.98 & $(0.91,1.06)$ \\
\hline Roflumilast + LABA & 0.87 & $(0.75, \mathrm{I} .0 \mathrm{I})$ \\
\hline Roflumilast + LAMA & 0.75 & $(0.64,0.87)$ \\
\hline Roflumilast + ICS & 0.82 & $(0.71,0.95)$ \\
\hline LABA + LAMA & 0.77 & $(0.67,0.87)$ \\
\hline $\mathrm{LABA}+\mathrm{ICS}$ & 0.85 & $(0.77,0.94)$ \\
\hline LAMA + ICS & 0.73 & $(0.64,0.82)$ \\
\hline Roflumilast + LABA + LAMA & 0.65 & $(0.54,0.77)$ \\
\hline Roflumilast + LABA + ICS & 0.71 & $(0.61,0.83)$ \\
\hline LAMA + LABA + ICS & 0.63 & $(0.54,0.73)$ \\
\hline Roflumilast + LABA + LAMA + ICS & 0.53 & $(0.43,0.64)$ \\
\hline
\end{tabular}

Note: Absolute treatment effects are expressed as mean exacerbations experienced per patient per patient-year.

Abbreviations: COPD, chronic obstructive pulmonary disease; ICS, inhaled corticosteroids; LABA, long-acting beta agonists; LAMA, long-acting antimuscarinic drugs; MTC, mixed-treatment comparison.

We applied both exacerbation rates and the outcome of ever having at least one event in our analyses and found almost identical effects. To our knowledge, this is the first COPD meta-analysis to examine this issue and it is reassuring that the findings are similar.

We considered a flexible framework for comparing competing interventions by allowing for the possibility that the total effect of a combination of treatments is equal to the sum of the effects of the components entering this combination. This additive assumption may be untenable in situations where particular pairs of components may have either bigger (synergistic) or smaller (antagonistic) effects than would be expected from the sum of their effects alone. The sparsity of our data prevented us from relaxing the additivity assumption.

Our study utilized evidence from all relevant RCTs of the prespecified interventions, regardless of whether they are in current clinical use. For example, we included trials evaluating a single intervention compared with placebo, even though neither one is used alone in clinical practice. This information increases the power of our analysis ${ }^{86}$ and, although this information is displayed in all results, only current combinations of clinical interest may be of use to clinicians. This issue is consistent with pairwise meta-analyses in addition to MTC analyses as it allows for increased power
Table 7 Probability each of the 15 treatments (ie, 5 single treatments plus 10 combinations of active treatments) for management of COPD is best, obtained on the basis of the additive main effects model considered in our secondary MTC analysis

\begin{tabular}{ll}
\hline Treatment & $\begin{array}{l}\text { Probability } \\
\text { treatment is best }\end{array}$ \\
\hline Placebo & 0.000 \\
Roflumilast & 0.000 \\
LABA & 0.000 \\
LAMA & 0.000 \\
ICS & 0.000 \\
Roflumilast + LABA & 0.000 \\
Roflumilast + LAMA & 0.000 \\
Roflumilast + ICS & 0.000 \\
LABA + LAMA & 0.000 \\
LABA + ICS & 0.000 \\
LAMA + ICS & 0.000 \\
Roflumilast + LABA + LAMA & 0.000 \\
Roflumilast + LABA + ICS & 0.000 \\
LAMA + LABA + ICS & 0.003 \\
Roflumilast + LABA + LAMA + ICS & 0.997
\end{tabular}

Abbreviations: COPD, chronic obstructive pulmonary disease; ICS, inhaled corticosteroids; LABA, long-acting beta agonists; LAMA, long-acting antimuscarinic drugs; MTC, mixed-treatment comparison.

and determines the magnitude of treatment effects compared with inert and less effective interventions.

In conclusion, our study represents the most up-to-date analysis of COPD treatments for the reduction of exacerbations that we are aware of. Our study demonstrates consistent effects of treatments that increase in combination.

\section{Disclosure}

This study was funded in part by Merck Sharp and Dohme Ltd and Nycomed Ltd. The funders had no role in the study, analysis, interpretation or reporting of this manuscript.

\section{References}

1. Barnes PJ. Chronic obstructive pulmonary disease: a growing but neglected global epidemic. PLoS Med. 2007;4:e112.

2. Zheng J, Yang L, Wu Y, et al. The efficacy and safety of combination salmeterol (50 microg)/fluticasone propionate (500 microg) inhalation twice daily via accuhaler in Chinese patients with COPD. Chest. 2007;132:1756-1763.

3. Rennard S, Tashkin D, McElhattan J, Goldman M, Ramachandran S, et al. Efficacy and tolerability of budesonide/formoterol in one hydrofluoroalkane pressurized metered-dose inhaler in patients with chronic obstructive pulmonary disease: results from a 1-year randomized controlled clinical trial. Drugs. 2009;69:549-565.

4. Lapperre T, Snoeck-Stroband J, Gosman M, et al. Effect of fluticasone with and without salmeterol on pulmonary outcomes in chronic obstructive pulmonary disease: a randomized trial. Ann Intern Med. 2009;151:517-527.

5. Tashkin D, Pearle J, Iezzoni D, Varghese S. Formoterol and tiotropium compared with tiotropium alone for treatment of COPD. COPD. 2009;6: $17-25$.

6. Calverley P, Rabe K, Goehring U, et al. Roflumilast in symptomatic chronic obstructive pulmonary disease: two randomised clinical trials. Lancet. 2009;374:685-694. 
7. Fabbri L, Calverley P, Izquierdo-Alonso J, et al. Roflumilast in moderate-to-severe chronic obstructive pulmonary disease treated with longacting bronchodilators: two randomised clinical trials. Lancet. 2009;374:695-703.

8. Rabe K, Bateman E, O'Donnell D, et al. Roflumilast - an oral antiinflammatory treatment for chronic obstructive pulmonary disease: a randomised controlled trial. Lancet. 2005;366:563-571.

9. Calverley P, Sanchez-Toril F, McIvor A, et al. Effect of 1-year treatment with roflumilast in severe chronic obstructive pulmonary disease. Am J Respir Crit Care Med. 2007;176:154-161.

10. Sin DD, McAlister FA, Man SF, Anthonisen NR. Contemporary management of chronic obstructive pulmonary disease: scientific review. JAMA. 2003;290:2301-2312.

11. Sobieraj DM, White CM, Coleman CI. Benefits and risks of adjunctive inhaled corticosteroids in chronic obstructive pulmonary disease: a meta-analysis. Clin Ther.2008;30:1416-1425.

12. Nannini L, Cates C, Lasserson T, Poole P. Combined corticoster- oid and long-acting beta-agonist in one inhaler versus pla- cebo for chronic obstructive pulmonary disease. Cochrane Database Syst Rev. 2007;4:CD003794.

13. Yang IA, Fong KM, Sim EH, Black PN, Lasserson TJ. Inhaled corticosteroids for stable chronic obstructive pulmonary disease. Cochrane Database Syst Rev. 2007;2:CD002991.

14. Wilt TJ, Niewoehner D, Macdonald R, Kane RL. Management of stable chronic obstructive pulmonary disease: a systematic review for a clinical practice guideline. Ann Intern Med. 2007;147:639-653.

15. Nannini L, Cates C, Lasserson T, Poole P. Combined corticosteroid and long-acting beta-agonist in one inhaler versus long-acting betaagonists for chronic obstructive pulmonary disease. Cochrane Database Syst Rev. 2007;4:CD006829.

16. Nannini L, Cates C, Lasserson T, Poole P. Combined corticoster- oid and long-acting beta-agonist in one inhaler versus inhaled steroids for chronic obstructive pulmonary disease. Cochrane Database Syst Rev. 2007;4:CD006826.

17. Puhan M, Bachmann L, Kleijnen J, Ter Riet G, Kessells A. Inhaled drugs to reduce exacerbations in patients with chronic obstructive pulmonary disease: a network meta-analysis. BMC Med. 2009;7:2.

18. Baker W, Baker E, Coleman C. Pharmacologic treatments for chronic obstructive pulmonary disease: a mixed-treatment comparison meta-analysis. Pharmacotherapy. 2009;29:891-905.

19. Aaron SD, Fergusson D, Marks GB, et al; for the Canadian Thoracic Society/Canadian Respiratory Clinical Research Consortium. Counting, analysing and reporting exacerbations of COPD in randomised controlled trials. Thorax. 2008;63:122-128.

20. Suissa S. Statistical treatment of exacerbations in therapeutic trials of chronic obstructive pulmonary disease. Am J Respir Crit Care Med. 2006;173:842-846.

21. American Thoracic Society, European Respiratory Society. Standards for the diagnosis and management of patients with COPD. Available from: http://www.thoracic.org/clinical/copd-guidelines/resources/ copddoc.pdf. Accessed January 10, 2011.

22. Rodriguez-Roisin R. Toward a consensus definition for COPD exacerbations. Chest. 2000;117:398S-401S.

23. Salanti G, Kavvoura FK, Ioannidis JP. Exploring the geometry of treatment networks. Ann Intern Med. 2008;148:544-553.

24. Lu G, Ades AE. Combination of direct and indirect evidence in mixed treatment comparisons. Stat Med. 2004;23:3105-3124.

25. Sutton A, Ades AE, Cooper N, Abrams K. Use of indirect and mixed treatment comparisons for technology assessment. Pharmacoeconomics. 2008;26:753-767.

26. Cooper NJ, Sutton AJ, Lu G, Khunti K. Mixed comparison of stroke prevention treatments in individuals with nonrheumatic atrial fibrillation. Arch Intern Med 2006;166:1269-1275.

27. Rennard SI, Calverley PM, Goehring UM, Bredenbroker D, Martinez FJ. Reduction of exacerbations by the PDE4 inhibitor roflumilast - the importance of defining different subsets of patients with COPD. Respir Res. 2011;12:18.
28. Welton NJ, Caldwell DM, Adamopoulos E, Vedhara K. Mixed treatment comparison meta-analysis of complex interventions: psychological interventions in coronary heart disease. Am J Epidemiol. 2009;169: $1158-1165$.

29. Spiegelhalter DJ, Best NG, Carlin BP, van der Linde A. Bayesian measures of model compexity and fit. Journal of the Royal Statistical Society. 2002;64:583-639.

30. DerSimonian R, Laird N. Meta-analysis in clinical trials. Control Clin Trials. 1986;7:177-188.

31. Aaron S, Vandemheen K, Fergusson D, et al. Tiotropium in combination with placebo, salmeterol, or fluticasone-salmeterol for treatment of chronic obstructive pulmonary disease: a randomized trial. Ann Intern Med. 2007;146:545-555.

32. Anzueto A, Ferguson G, Feldman G, et al. Effect of fluticasone propionate/salmeterol (250/50) on COPD exacerbations and impact on patient outcomes. COPD. 2009;6:320-329.

33. Bourbeau J, Rouleau M, Boucher S. Randomised controlled trial of inhaled corticosteroids in patients with chronic obstructive pulmonary disease. Thorax. 1998;53:477-482.

34. Brusasco V, Hodder R, Miravitlles M, et al. Health outcomes following treatment for six months with once daily tiotropium compared with twice daily salmeterol in patients with COPD. Thorax. 2003;58:399-404.

35. Burge P, Calverley P, Jones P, et al. Randomised, double blind, placebo controlled study of fluticasone propionate in patients with moderate to severe chronic obstructive pulmonary disease: the ISOLDE trial. $B M J$. 2000;320:1297-1303.

36. Calverley P, Anderson J, Celli B, et al. Salmeterol and fluticasone propionate and survival in chronic obstructive pulmonary disease. $N$ Engl J Med. 2007;356:775-789.

37. Calverley P, Boonsawat W, Cseke Z, et al. Maintenance therapy with Budesonide and Formoterol in chronic obstructive pulmonary disease. Eur Respir J. 2003;22:912-919.

38. Calverley P, Pauwels R, Vestbo J, et al. Combined salmeterol and fluticasone in the treatment of chronic obstructive pulmonary disease: a randomised controlled trial. Lancet. 2003;361:449-456.

39. Casaburi R, Mahler D, Jones P, et al. A long-term evaluation of oncedaily inhaled Tiotropium in chronic obstructive pulmonary disease. Eur Respir J. 2002;19:217-224.

40. Chan C, Maltais F, Sigouin C, et al. A randomized controlled trial to assess the efficacy of Tiotropium in Canadian patients with chronic obstructive pulmonary disease. Can Respir J. 2007;14:465-472.

41. Chapman K, Arvidsson P, Chuchalin A, et al. The addition of salmeterol 50 microg bid to anticholinergic treatment in patients with COPD: a randomized, placebo controlled trial. Chronic obstructive pulmonary disease. Can Respir J. 2002;9:178-185.

42. Dusser D, Bravo M, Iacono P. The effect of tiotropium on exacerbations and airflow in patients with COPD. Eur Respir J. 2006;27:547-555.

43. Ferguson G, Anzueto A, Fei R, et al. Effect of fluticasone propionate/ salmeterol (250/50 microg) or salmeterol (50 microg) on COPD exacerbations. Respir Med. 2008;102:1099-1108.

44. Kardos P, Wencker M, Glaab T, Vogelmeier C. Impact of Salmeterol/ fluticasone propionate versus salmeterol on exacerbations in severe chronic obstructive pulmonary disease. Am J Respir Crit Care Med. 2007;175:144-149.

45. Niewoehner D, Rice K, Cote C, et al. Prevention of exacerbations of chronic obstructive pulmonary disease with Tiotropium, a once-daily inhaled anticholinergic bronchodilator: a randomized trial. Ann Intern Med. 2005;143:317-326.

46. Paggiaro P, Dahle R, Bakran I, et al. Multicentre randomised placebocontrolled trial of inhaled fluticasone propionate in patients with chronic obstructive pulmonary disease. International COPD Study Group. Lancet. 1998;351:773-780.

47. Powrie D, Wilkinson T, Donaldson G, et al. Effect of tiotropium on sputum and serum inflammatory markers and exacerbations in COPD. Eur Respir J. 2007;30:472-478.

48. Stockley R, Chopra N, Rice L. Addition of salmeterol to existing treatment in patients with COPD: a 12 month study. Thorax. 2006;61: 122-128. 
49. Szafranski W, Cukier A, Ramirez A, et al. Efficacy and safety of budesonide/formoterol in the management of chronic obstructive pulmonary disease. Eur Respir J. 2003;21:74-81.

50. Tashkin D, Celli B, Senn S, et al. A 4-year trial of tiotropium in chronic obstructive pulmonary disease. $N$ Engl J Med. 2008;359:1543-1554.

51. Tonnel A, Perez T, Grosbois J, et al. Effect of tiotropium on healthrelated quality of life as a primary efficacy endpoint in COPD. Int J Chron Obstruct Pulmon Dis. 2008:3:301-310.

52. Vogelmeier C, Kardos P, Harari S, et al. Formoterol mono- and combination therapy with tiotropium in patients with COPD: a 6-month study. Respir Med. 2008;102:1511-1520.

53. Wedzicha J, Calverley P, Seemungal T, et al. The prevention of chronic obstructive pulmonary disease exacerbations by salmeterol/fluticasone propionate or tiotropium bromide. Am J Respir Crit Care Med. 2008 177:19-26.

54. Rossi A, Kristufek P, Levine B, et al. Comparison of the efficacy, tolerability, and safety of formoterol dry powder and oral, slow-release theophylline in the treatment of COPD. Chest. 2002;121: 1058-1069.

55. Baker W, Baker E, Coleman C. Pharmacologic treatments for chronic obstructive pulmonary disease: a mixed-treatment comparison meta-analysis. Pharmacotherapy. 2009;29:891-905.

56. Barnes N, Qiu Y, Pavord I, et al. Anti-inflammatory effects of salmeterol/fluticasone propionate in chronic obstructive lung disease. Am J Respir Crit Care Med. 2006;173:736-743.

57. Baumgartner R, Hanania N, Calhoun W, et al. Nebulized arformoterol in patients with COPD: a 12-week, multicenter, randomized, doubleblind, double-dummy, placebo- and active-controlled trial. Clin Ther. 2007;29:261-278.

58. Beeh K, Beier J, Buhl R, et al. Efficacy of tiotropium bromide (Spiriva) in patients with chronic-obstructive pulmonary disease (COPD) of different severities. Pneumologie. 2006;60:341-346.

59. Boyd G, Morice A, Pounsford M, et al. An evaluation of salmeterol in the treatment of chronic obstructive pulmonary disease (COPD). Eur Respir J. 1997;10:815-821.

60. Calverley P, Lee A, Towse L, et al. Effect of tiotropium bromide on circadian variation in airflow limitation in chronic obstructive pulmonary disease. Thorax. 2003;58:855-860.

61. Campbell M, Eliraz A, Johansson G, et al. Formoterol for maintenance and as-needed treatment of chronic obstructive pulmonary disease. Respir Med. 2005;99:1511-1520.

62. Casaburi R, Briggs D Jr, Donohue J, et al. The spirometric efficacy of once-daily dosing with tiotropium in stable COPD: a 13-week multicenter trial. The US Tiotropium Study Group. Chest. 2000;118: 1294-1302.

63. Celli B, Halpin D, Hepburn R, et al. Symptoms are an important outcome in chronic obstructive pulmonary disease clinical trials: results of a 3-month comparative study using the Breathlessness, Cough and Sputum Scale (BCSS). Respir Med. 2003;97:S35-S43.

64. Covelli H, Bhattacharya S, Cassino C, Conoscenti C, Kesten S. Absence of electrocardiographic findings and improved function with once-daily tiotropium in patients with chronic obstructive pulmonary disease. Pharmacotherapy. 2005;25:1708-1718.

65. Dahl R, Greefhorst L, Nowak D, et al. Inhaled formoterol dry powder versus ipratropium bromide in chronic obstructive pulmonary disease. Am J Respir Crit Care Med. 2001;164:778-784.

66. Dal Negro R, Pomari C, Tognella S, Micheletto C. Salmeterol and fluticasone 50 microg $/ 250$ microg bid in combination provides a better long-term control than salmeterol 50 microg bid alone and placebo in COPD patients already treated with theophylline. Pulm Pharmacol Ther. 2003;16:241-246.

67. Freeman D, Lee A, Price D. Efficacy and safety of tiotropium in COPD patients in primary care - the SPiRiva Usual CarE (SPRUCE) study. Respir Res. 2007;8:45.
68. Hanania N, Darken P, Horstman D, et al. The efficacy and safety of fluticasone propionate (250 microg)/salmeterol (50 microg) combined in the Diskus inhaler for the treatment of COPD. Chest. 2003;124: 834-843.

69. Hattotuwa K, Gizycki M, Ansari T, Jeffery P, Barnes N. The effects of inhaled fluticasone on airway inflammation in chronic obstructive pulmonary disease: a double-blind, placebo-controlled biopsy study. Am J Respi Crit Care Med. 2002;165:1592-1596.

70. Littner M, Ilowite J, Tashkin D, et al. Long-acting bronchodilation with once-daily dosing of tiotropium (Spiriva) in stable chronic obstructive pulmonary disease. Am J Respir Crit Care Med. 2000;161:1136-1142.

71. Llewellyn-Jones C, Harris T, Stockley R. Effect of fluticasone propionate on sputum of patients with chronic bronchitis and emphysema. Am J Respir Crit Care Med. 1996;153:616-621.

72. Mahler D, Donohue J, Barbee R, et al. Efficacy of salmeterol xinafoate in the treatment of COPD. Chest. 1999;115:957-965.

73. Mahler D, Wire P, Horstman D, et al. Effectiveness of fluticasone propionate and salmeterol combination delivered via the Diskus device in the treatment of chronic obstructive pulmonary disease. Am J Respir Crit Care Med. 2002;166:1084-1091.

74. O'Donnell D, Fluge T, Gerken F, et al. Effects of tiotropium on lung hyperinflation, dyspnoea and exercise tolerance in COPD. Eur Respir J. 2004;23:832-840.

75. O'Donnell D, Sciurba F, Celli B, et al. Effect of fluticasone propionate/ salmeterol on lung hyperinflation and exercise endurance in COPD. Chest. 2006;130:647-656.

76. Paggiaro P, Vagaggini B, Di Franco A, et al. Efficacy of nebulized flunisolide combined with salbutamol and ipratropium bromide in stable patients with moderate-to-severe chronic obstructive pulmonary disease. Respiration. 2006;73:603-609.

77. Rennard S, Anderson W, ZuWallack R, et al. Use of a long-acting inhaled beta2-adrenergic agonist, salmeterol xinafoate, in patients with chronic obstructive pulmonary disease. Am J Respir Crit Care Med. 2001;163:1087-1092.

78. Van der Valk P, Monninkhof E, van der Palen J, Zielhuis G, van Herwaarden C. Effect of discontinuation of inhaled corticosteroids in patients with chronic obstructive pulmonary disease: the COPE study. Am J Respir Crit Care Med. 2002;166:1358-1363.

79. Van Noord J, Aumann J, Janssens E, et al. Comparison of tiotropium once daily, formoterol twice daily and both combined once daily in patients with COPD. Eur Respir J. 2005;26:214-222.

80. Van Noord J, de Munck D, Bantje T, et al. Long-term treatment of chronic obstructive pulmonary disease with salmeterol and the additive effect of ipratropium. Eur Respir J. 2000;15:878-885.

81. Verkindre C, Bart F, Aguilaniu B, et al. The effect of tiotropium on hyperinflation and exercise capacity in chronic obstructive pulmonary disease. Respiration. 2006;73:420-427.

82. Wadbo M, Löfdahl C, Larsson K, et al. Effects of formoterol and ipratropium bromide in COPD: a 3-month placebo-controlled study. Eur Respir J. 2002;20:1138-1146.

83. Weir D, Bale G, Bright P, Burge P. A double-blind placebo-controlled study of the effect of inhaled beclomethasone dipropionate for 2 years in patients with nonasthmatic chronic obstructive pulmonary disease. Clin Exp Allergy. 1999;29:125-128.

84. Donohue J, van Noord J, Bateman E, et al. A 6-month, placebocontrolled study comparing lung function and health status changes in COPD patients treated with tiotropium or salmeterol. Chest. 2002;122:47-55.

85. Moayyedi P. Meta-analysis: Can we mix apples and oranges? Am J Gastroenterol. 2004;99:2297-2301.

86. Higgins JP, Whitehead A. Borrowing strength from external trials in a meta-analysis. Stat Med. 1996;15:2733-2749. 


\section{Appendix I}

Description and WinBUGS implementation of primary analysis model. Let $A, B, C, D, E, F, G, H, I$ and $J$ denote the treatments placebo, roflumilast, LABA, LAMA, ICS, roflumilast + LABA, roflumilast + LAMA, LABA + LAMA, ICS + LABA and ICS + LAMA + LABA, respectively. Assume that $A$ is the reference (or baseline) treatment for the analysis. For each trial $j$, denote the total number of exacerbations in COPD observed for the $n_{j k}$ patients allocated to treatment $k$ by $r_{j k}$. Also, let $p y_{j k}$ denote the patient-years of follow-up in trial $j$ on treatment $k$.

Using this notation, the random-effects Poisson regression model used in our primary analysis can be expressed as:

$$
\begin{gathered}
r_{j k} \sim \operatorname{Poisson}\left(\lambda_{j k}\right) \text { for trial } j, \text { treatment } k \\
\log \left(\lambda_{j k}\right)=\left\{\begin{array}{l}
\log \left(p y_{j k} / 1000\right)+\mu_{j A} \quad \text { if } \quad k=A \\
\log \left(p y_{j k} / 1000\right)+\mu_{j A}+\delta_{j k A} \quad \text { if } k \neq A
\end{array}\right. \\
\delta_{j k A} \sim \operatorname{Normal}\left(d_{k A}, \sigma^{2}\right)
\end{gathered}
$$

Here, $\lambda_{j k}$ is the expected number of exacerbations in COPD in trial $j$ for treatment $k$ and represents the mean of the Poisson distribution in trial $j$ under treatment $k$. Also, $\mu_{j A}$ is the log rate of an exacerbation in COPD in trial $j$ on the baseline treatment $A$, and $\delta_{j k A}$ is the trial-specific $\log$ rate ratio of the active treatment $k$ relative to the baseline treatment $A$. These trial-specific log rate ratios are drawn from a random effects distribution: $\delta_{j k A} \sim \operatorname{Normal}\left(d_{k A}, \sigma^{2}\right)$. The pooled $\log$ rate ratios $d_{k A}$ for treatment $k$ relative to the baseline treatment $A$ are "baseline" parameters which are used to derive the "functional parameters" $d_{k l}$ representing the pooled log rate ratios of the active treatment $k$ relative to the active treatment $l$ via the consistency equation $d_{k l}=d_{l A}-d_{k A}$. The between-study variance $\sigma^{2}$ is a heterogeneity parameter that quantifies the extent of the variation between the results of the different studies included in the analysis. Note that this variance is assumed constant for all pairwise treatment comparisons.

The above model was fitted to the data using WinBUGS (Version 1.4; MRC Biostatistics Unit). For this model, two MCMC chains were run for 100,000 iterations after a 'burn-in' of 20,000 in order to ensure convergence of the MCMC sampler. Posterior inference was conducted after discarding the 'burn-in' iterations, based on 20,000 samples. The prior distributions placed on parameters in this model were vague and were specified as follows:

$$
\begin{gathered}
\mu_{j A} \sim \operatorname{Normal}(0,10000) \\
d_{k A} \sim \operatorname{Normal}(0,10000) \\
\sigma \sim \operatorname{Uniform}(0,10)
\end{gathered}
$$


Appendix Table I Estimated rate ratios and associated $95 \% \mathrm{Cl}$ for the relative effects of pairs of treatments for the management of COPD, produced by the fixed-effect MTC model without covariates

\begin{tabular}{|c|c|c|}
\hline \multirow[t]{2}{*}{ Treatment vs comparator } & \multicolumn{2}{|c|}{$\begin{array}{l}\text { Fixed-effect MTC } \\
\text { model }\end{array}$} \\
\hline & Rate ratio & $95 \% \mathrm{Cl}$ \\
\hline Roflumilast vs placebo & 0.85 & $(0.81,0.89)$ \\
\hline LABA vs placebo & 0.83 & $(0.81,0.86)$ \\
\hline LAMA vs placebo & 0.81 & $(0.79,0.83)$ \\
\hline ICS vs placebo & 0.79 & $(0.77,0.82)$ \\
\hline Roflumilast + LABA vs placebo & 0.66 & $(0.58,0.76)$ \\
\hline Roflumilast + LAMA vs placebo & 0.68 & $(0.58,0.79)$ \\
\hline LABA + LAMA vs placebo & 0.87 & $(0.72,1.05)$ \\
\hline ICS + LABA vs placebo & 0.70 & $(0.68,0.72)$ \\
\hline ICS + LAMA + LABA vs placebo & 0.74 & $(0.60,0.90)$ \\
\hline LABA vs roflumilast & 0.98 & $(0.93,1.04)$ \\
\hline LAMA vs roflumilast & 0.96 & $(0.91,1.01)$ \\
\hline ICS vs roflumilast & 0.93 & $(0.88,0.99)$ \\
\hline Roflumilast + LABA vs roflumilast & 0.78 & $(0.68,0.90)$ \\
\hline Roflumilast + LAMA vs roflumilast & 0.80 & $(0.68,0.94)$ \\
\hline LABA + LAMA vs roflumilast & 1.03 & $(0.85,1.24)$ \\
\hline ICS + LABA vs roflumilast & 0.82 & $(0.78,0.87)$ \\
\hline ICS + LAMA + LABA vs roflumilast & 0.88 & $(0.7 \mathrm{I}, \mathrm{I} .07)$ \\
\hline LAMA vs LABA & 0.97 & $(0.94,1.01)$ \\
\hline ICS vs LABA & 0.95 & $(0.92,0.98)$ \\
\hline Roflumilast + LABA vs LABA & 0.79 & $(0.70,0.90)$ \\
\hline Roflumilast + LAMA vs LABA & 0.82 & $(0.70,0.95)$ \\
\hline LABA + LAMA vs LABA & 1.05 & $(0.87,1.26)$ \\
\hline ICS + LABA vs LABA & 0.84 & $(0.81,0.87)$ \\
\hline ICS + LAMA + LABA vs LABA & 0.89 & $(0.73,1.08)$ \\
\hline ICS vs LAMA & 0.98 & $(0.94,1.01)$ \\
\hline Roflumilast + LABA vs LAMA & 0.82 & $(0.71,0.93)$ \\
\hline Roflumilast + LAMA vs LAMA & 0.84 & $(0.72,0.97)$ \\
\hline LABA + LAMA vs LAMA & 1.08 & $(0.89,1.29)$ \\
\hline ICS + LABA vs LAMA & 0.86 & $(0.83,0.89)$ \\
\hline ICS + LAMA + LABA vs LAMA & 0.92 & $(0.75, I . I I)$ \\
\hline Roflumilast + LABA vs ICS & 0.84 & $(0.73,0.96)$ \\
\hline Roflumilast + LAMA vs ICS & 0.86 & $(0.73,1.00)$ \\
\hline LABA + LAMA vs ICS & I.II & $(0.91,1.33)$ \\
\hline ICS + LABA vs ICS & 0.88 & $(0.85,0.92)$ \\
\hline ICS + LAMA + LABA vs ICS & 0.94 & $(0.76,1.14)$ \\
\hline Roflumilast + LAMA vs roflumilast + LABA & 1.03 & $(0.83,1.25)$ \\
\hline LABA + LAMA vs roflumilast + LABA & 1.33 & $(1.05,1.66)$ \\
\hline ICS + LABA vs roflumilast + LABA & 1.06 & $(0.92,1.21)$ \\
\hline LAMA + ICS + LABA vs roflumilast + LABA & 1.13 & $(0.88,1.42)$ \\
\hline LABA + LAMA vs roflumilast + LAMA & 1.29 & $(1.02,1.64)$ \\
\hline ICS + LABA vs roflumilast + LAMA & 1.03 & $(0.89,1.21)$ \\
\hline ICS + LAMA + LABA vs roflumilast + LAMA & 1.10 & $(0.85,1.40)$ \\
\hline ICS + LABA vs LABA + LAMA & 0.81 & $(0.66,0.97)$ \\
\hline ICS + LAMA + LABA vs LABA + LAMA & 0.85 & $(0.70,1.03)$ \\
\hline ICS + LAMA + LABA vs ICS + LABA & 1.06 & $(0.87,1.29)$ \\
\hline
\end{tabular}

Note: $A$ rate ratio smaller (larger) than $I$ indicates that the treatment is associated with a reduction (increase) in the rate of exacerbations in COPD relative to the comparator.

Abbreviations: COPD, chronic obstructive pulmonary disease; ICS, inhaled corticosteroids; LABA, long-acting beta agonists; LAMA, long-acting antimuscarinic drugs; MTC, mixed-treatment comparison.
Appendix Table 2 Absolute treatment effects corresponding to the 10 treatments for the management of COPD, as derived from the fixed-effect MTC model without covariates

\begin{tabular}{lll}
\hline Treatment & Absolute treatment effect & $\mathbf{9 5 \%} \mathbf{~ C l}$ \\
\hline Placebo & 1.17 & $(\mathrm{I} .15, \mathrm{I} .20)$ \\
Roflumilast & 0.99 & $(0.94,1.04)$ \\
LABA & 0.98 & $(0.95,1.02)$ \\
LAMA & 0.96 & $(0.93,0.99)$ \\
ICS & 0.94 & $(0.90,0.97)$ \\
Roflumilast + LABA & 0.78 & $(0.68,0.89)$ \\
Roflumilast + LAMA & 0.80 & $(0.69,0.93)$ \\
LABA + LAMA & 0.97 & $(0.81,1.15)$ \\
ICS + LABA & 0.82 & $(0.80,0.85)$ \\
ICS + LAMA + LABA & 0.71 & $(0.60,0.84)$ \\
\hline
\end{tabular}

Note: Absolute treatment effects are expressed as mean exacerbations experienced per patient per patient-year.

Abbreviations: $\mathrm{Cl}$, confidence interval; COPD, chronic obstructive pulmonary disease; ICS, inhaled corticosteroids; LABA, long-acting beta agonists; LAMA, longacting antimuscarinic drugs; MTC, mixed-treatment comparison. 
Appendix Table 3 Probability that each of the 10 treatments for management of COPD is best, obtained on the basis of the fixed-effect MTC model without covariates

\begin{tabular}{|c|c|c|c|c|c|c|c|c|c|c|}
\hline Treatment & PI & $\mathbf{P 2}$ & P3 & P4 & P5 & P6 & P7 & P8 & P9 & PIO \\
\hline Placebo & 0.000 & 0.000 & 0.000 & 0.000 & 0.000 & 0.000 & 0.000 & 0.001 & $0.07 \mid$ & 0.928 \\
\hline Roflumilast & 0.000 & 0.000 & 0.000 & 0.002 & 0.016 & 0.061 & 0.191 & 0.426 & 0.304 & 0.000 \\
\hline LABA & 0.000 & 0.000 & 0.000 & 0.001 & 0.016 & 0.121 & 0.409 & 0.357 & 0.096 & 0.000 \\
\hline LAMA & 0.000 & 0.000 & 0.000 & 0.019 & 0.199 & 0.506 & 0.240 & 0.032 & 0.003 & 0.000 \\
\hline ICS & 0.000 & 0.000 & 0.007 & 0.239 & 0.531 & 0.189 & 0.032 & 0.002 & 0.000 & 0.000 \\
\hline Roflumilast + LABA & 0.502 & 0.279 & 0.145 & 0.065 & 0.008 & 0.001 & 0.000 & 0.000 & 0.000 & 0.000 \\
\hline Roflumilast + LAMA & 0.335 & 0.284 & 0.219 & 0.130 & 0.020 & 0.005 & 0.003 & 0.002 & 0.001 & 0.000 \\
\hline LABA + LAMA & 0.000 & 0.003 & 0.009 & 0.032 & 0.120 & 0.066 & 0.081 & 0.109 & 0.508 & 0.072 \\
\hline ICS + LABA & 0.056 & 0.305 & 0.473 & 0.161 & 0.005 & 0.000 & 0.000 & 0.000 & 0.000 & 0.000 \\
\hline ICS + LAMA + LABA & 0.106 & 0.128 & 0.146 & 0.352 & 0.084 & 0.052 & 0.044 & 0.070 & 0.017 & 0.001 \\
\hline
\end{tabular}

Note: PI-PIO refers to probability that each is Ist, 2 nd, ... $k$ best.

Abbreviations: COPD, chronic obstructive pulmonary disease; ICS, inhaled corticosteroids; LABA, long-acting beta agonists; LAMA, long-acting antimuscarinic drugs; MTC, mixed-treatment comparison.

Appendix Table 4 Estimated relative risks and $95 \%$ confidence intervals for all pairs of treatments produced by the randomeffects MTC model without covariates. Binomial model

\begin{tabular}{lll}
\hline Treatment vs comparator & \multicolumn{2}{l}{$\begin{array}{l}\text { Random-effects } \\
\text { model }\end{array}$} \\
\cline { 2 - 3 } & Relative risk & $95 \%$ Cl \\
\hline Roflumilast vs placebo & 0.90 & $(0.79,0.97)$ \\
LABA vs placebo & 0.88 & $(0.79,0.96)$ \\
LAMA vs placebo & 0.83 & $(0.75,0.90)$ \\
ICS vs placebo & 0.79 & $(0.68,0.89)$ \\
Roflumilast + LABA vs placebo & 0.74 & $(0.53,0.96)$ \\
Roflumilast + LAMA vs placebo & 0.63 & $(0.44,0.85)$ \\
LABA + LAMA vs placebo & 0.77 & $(0.56,1.00)$ \\
ICS + LABA vs placebo & 0.78 & $(0.69,0.87)$ \\
ICS + LAMA + LABA vs placebo & 0.72 & $(0.48,1.00)$ \\
LABA vs roflumilast & 0.97 & $(0.82,1.12)$ \\
LAMA vs roflumilast & 0.92 & $(0.77,1.06)$ \\
ICS vs roflumilast & 0.88 & $(0.71,1.03)$ \\
Roflumilast + LABA vs roflumilast & 0.82 & $(0.57,1.09)$ \\
Roflumilast + LAMA vs roflumilast & 0.70 & $(0.47,0.97)$ \\
LABA + LAMA vs roflumilast & 0.86 & $(0.60,1.14)$ \\
ICS + LABA vs roflumilast & 0.87 & $(0.71,1.02)$ \\
ICS + LAMA + LABA vs roflumilast & 0.80 & $(0.52,1.13)$ \\
LAMA vs LABA & 0.94 & $(0.82,1.07)$ \\
ICS vs LABA & 0.89 & $(0.76,1.02)$ \\
Roflumilast + LABA vs LABA & 0.83 & $(0.60,1.09)$ \\
Roflumilast + LAMA vs LABA & 0.70 & $(0.47,0.99)$ \\
LABA + LAMA vs LABA & 0.87 & $(0.61,1.18)$ \\
ICS + LABA vs LABA & 0.88 & $(0.78,0.98)$ \\
\hline & & $($ Continued)
\end{tabular}

\section{Appendix Table 4 (Continued)}

\begin{tabular}{|c|c|c|}
\hline \multirow[t]{2}{*}{ Treatment vs comparator } & \multicolumn{2}{|c|}{$\begin{array}{l}\text { Random-effects MTC } \\
\text { model }\end{array}$} \\
\hline & Relative risk & $95 \% \mathrm{Cl}$ \\
\hline ICS + LAMA + LABA vs LAMA & 0.81 & $(0.51,1.18)$ \\
\hline ICS vs LAMA & 0.96 & $(0.84,1.07)$ \\
\hline Roflumilast + LABA vs LAMA & 0.90 & $(0.68,1.14)$ \\
\hline Roflumilast + LAMA vs LAMA & 0.79 & $(0.58,1.02)$ \\
\hline LABA + LAMA vs LAMA & 0.94 & $(0.72,1.17)$ \\
\hline ICS + LABA vs LAMA & 0.95 & $(0.85,1.05)$ \\
\hline ICS + LAMA + LABA vs LAMA & 0.89 & $(0.63,1.16)$ \\
\hline Roflumilast + LABA vs ICS & 0.93 & $(0.62, I .31)$ \\
\hline Roflumilast + LAMA vs ICS & 0.77 & $(0.49,1.14)$ \\
\hline LABA + LAMA vs ICS & 0.99 & $(0.65, I .40)$ \\
\hline ICS + LABA vs ICS & 0.99 & $(0.83,1.17)$ \\
\hline ICS + LAMA + LABA vs ICS & 0.91 & $(0.55,1.40)$ \\
\hline Roflumilast + LAMA vs roflumilast + LABA & 0.86 & $(0.51,1.31)$ \\
\hline LABA + LAMA vs roflumilast + LABA & 1.07 & $(0.66,1.55)$ \\
\hline ICS + LABA vs roflumilast + LABA & 1.08 & $(0.77, \mathrm{I} .42)$ \\
\hline LAMA + ICS + LABA vs roflumilast + LABA & 1.00 & $(0.57,1.53)$ \\
\hline LABA + LAMA vs roflumilast + LAMA & 1.27 & $(0.77,1.88)$ \\
\hline ICS + LABA vs roflumilast + LAMA & 1.28 & $(0.87,1.76)$ \\
\hline ICS + LAMA + LABA vs roflumilast + LAMA & 1.19 & $(0.67,1.84)$ \\
\hline ICS + LABA vs LABA + LAMA & 1.02 & $(0.72,1.36)$ \\
\hline ICS + LAMA + LABA vs LABA + LAMA & 0.94 & $(0.62,1.32)$ \\
\hline ICS + LAMA + LABA vs ICS + LABA & 0.93 & $(0.6 \mathrm{I}, \mathrm{I} .30)$ \\
\hline
\end{tabular}

Abbreviations: COPD, chronic obstructive pulmonary disease; ICS, inhaled corticosteroids; LABA, long-acting beta agonists; LAMA, long-acting antimuscarinic drugs; MTC, mixed-treatment comparison. 
Appendix Table 5 Absolute treatment effects obtained from the random-effects MTC model on binomial model

\begin{tabular}{lll}
\hline Treatment & Absolute treatment effect & $\mathbf{9 5 \%} \mathbf{~ C l}$ \\
\hline Placebo & 0.35 & $(0.33,0.36)$ \\
Roflumilast & 0.31 & $(0.27,0.36)$ \\
LABA & 0.30 & $(0.27,0.33)$ \\
LAMA & 0.28 & $(0.25,0.3 \mathrm{I})$ \\
ICS & 0.26 & $(0.23,0.30)$ \\
Roflumilast + LABA & 0.25 & $(0.17,0.33)$ \\
Roflumilast + LAMA & 0.21 & $(0.14,0.29)$ \\
LABA + LAMA & 0.26 & $(0.18,0.35)$ \\
ICS + LABA & 0.26 & $(0.23,0.29)$ \\
ICS + LAMA + LABA & 0.24 & $(0.15,0.35)$ \\
\hline
\end{tabular}

Note: Absolute treatment effects are expressed as mean exacerbations experienced per patient per patient-year.

Abbreviations: COPD, chronic obstructive pulmonary disease; ICS, inhaled corticosteroids; LABA, long-acting beta agonists; LAMA, long-acting antimuscarinic drugs; MTC, mixed-treatment comparison.

Appendix Table 6 Probability each of the 10 treatments for management of COPD is best, obtained on the basis of the random-effects MTC model without covariates. Binomial model

\begin{tabular}{ll}
\hline Treatment & Probability treatment is best \\
\hline Placebo & 0.000 \\
Roflumilast & 0.000 \\
LABA & 0.000 \\
LAMA & 0.000 \\
ICS & 0.011 \\
Roflumilast + LABA & 0.147 \\
Roflumilast + LAMA & 0.562 \\
LABA + LAMA & 0.061 \\
ICS + LABA & 0.010 \\
ICS + LAMA + LABA & 0.207 \\
\hline
\end{tabular}

Abbreviations: COPD, chronic obstructive pulmonary disease; ICS, inhaled corticosteroids; LABA, long-acting beta agonists; LAMA, long-acting antimuscarinic drugs; MTC, mixed-treatment comparison.
Appendix Table 7 Random effects, direct (head to head) evaluation using DerSimmonian Laird random-effects model. Exacerbation rates

\begin{tabular}{lll}
\hline Treatment vs Comparator & \multicolumn{2}{l}{$\begin{array}{l}\text { Random-effects direct } \\
\text { evidence }\end{array}$} \\
\cline { 2 - 3 } & Rate ratio & $\mathbf{9 5 \%} \mathbf{~ C l}$ \\
\hline Roflumilast vs placebo & 0.85 & $(0.78-0.93)$ \\
LABA vs placebo & 0.87 & $(0.79-0.96)$ \\
LAMA vs placebo & 0.74 & $(0.64-0.84)$ \\
ICS vs placebo & 0.81 & $(0.74-0.90)$ \\
ICS + LABA vs placebo & 0.72 & $(0.66-0.79)$ \\
LAMA vs LABA & 0.91 & $(0.80-1.06)$ \\
Roflumilast + LABA vs LABA & 0.79 & $(0.70-0.91)$ \\
ICS + LABA vs LABA & 0.81 & $(0.75-0.86)$ \\
ICS + LABA + LAMA vs LAMA & 0.91 & $(0.75-1.11)$ \\
Roflumilast + LAMA vs LAMA & 0.83 & $(0.72-0.97)$ \\
LABA + LAMA vs LAMA & 1.07 & $(0.94-1.22)$ \\
ICS + LABA vs LAMA & 0.97 & $(0.93-1.02)$ \\
ICS + LABA + LAMA vs LABA + LAMA & 0.85 & $(0.74-0.97)$ \\
\hline
\end{tabular}

Abbreviations: COPD, chronic obstructive pulmonary disease; ICS, inhaled corticosteroids; LABA, long-acting beta agonists; LAMA, long-acting antimuscarinic drugs; MTC, mixed-treatment comparison.

Appendix Table 8 Random effects, direct (head to head) evaluation using DerSimmonian Laird random-effects model. Binomial model

\begin{tabular}{lll}
\hline Treatment vs comparator & \multicolumn{2}{l}{$\begin{array}{l}\text { Random-effects direct } \\
\text { evidence }\end{array}$} \\
\cline { 2 - 3 } & Relative risk & $\mathbf{9 5 \%} \mathbf{C l}$ \\
\hline Roflumilast vs placebo & 0.90 & $(0.85-0.95)$ \\
LABA vs placebo & 0.85 & $(0.78-0.91)$ \\
LAMA vs placebo & 0.84 & $(0.77-0.92)$ \\
ICS vs placebo & 0.69 & $(0.57-0.83)$ \\
ICS + LABA vs placebo & 0.70 & $(0.57-0.88)$ \\
LAMA vs LABA & 0.95 & $(0.82-1.10)$ \\
Roflumilast + LABA vs LABA & 0.83 & $(0.83-1.00)$ \\
ICS + LABA vs LABA & 0.90 & $(0.83-0.98)$ \\
ICS + LABA + LAMA vs LAMA & 0.96 & $(0.80-1.14)$ \\
Roflumilast + LAMA vs LAMA & 0.73 & $(0.62-0.87)$ \\
LABA + LAMA vs LAMA & 0.83 & $(0.46-1.51)$ \\
ICS + LABA vs LAMA & 1.05 & $(0.96-1.15)$ \\
ICS + LABA + LAMA vs LABA + LAMA & 0.93 & $(0.82-1.05)$ \\
\hline
\end{tabular}

Abbreviations: COPD, chronic obstructive pulmonary disease; ICS, inhaled corticosteroids; LABA, long-acting beta agonists; LAMA, long-acting antimuscarinic drugs; MTC, mixed-treatment comparison. 
Appendix Table 9 Estimated rate ratios and associated $95 \% \mathrm{Cl}$ for the relative effects of pairs of treatments for the management of COPD, produced by random effects MTC involving previously unpublished roflumilast data (M2-I I I trial) $)^{28}$

\begin{tabular}{|c|c|}
\hline \multirow[t]{2}{*}{ Treatment vs comparator } & \multirow{2}{*}{$\frac{\text { Rate ratio }(95 \% \mathrm{Cl})}{\text { Original } \mathrm{MTC} \text { analysis }}$} \\
\hline & \\
\hline Roflumilast vs placebo & $0.83(0.70,0.97)$ \\
\hline LABA vs placebo & $0.84(0.75,0.93)$ \\
\hline LAMA vs placebo & $0.74(0.66,0.8 I)$ \\
\hline ICS vs placebo & $0.80(0.71,0.89)$ \\
\hline Roflumilast + LABA vs placebo & $0.67(0.48,0.91)$ \\
\hline Roflumilast + LAMA vs placebo & $0.62(0.45,0.84)$ \\
\hline LABA + LAMA vs placebo & $0.80(0.56,1.11)$ \\
\hline ICS + LABA vs placebo & $0.69(0.61,0.77)$ \\
\hline ICS + LAMA + LABA vs placebo & $0.68(0.47,0.94)$ \\
\hline LABA vs roflumilast & $1.01(0.83,1.23)$ \\
\hline LAMA vs roflumilast & $0.89(0.73,1.07)$ \\
\hline ICS vs roflumilast & $0.97(0.79,1.18)$ \\
\hline Roflumilast + LABA vs roflumilast & $0.81(0.56,1.14)$ \\
\hline Roflumilast + LAMA vs roflumilast & $0.75(0.52,1.06)$ \\
\hline LABA + LAMA vs roflumilast & $0.97(0.65,1.39)$ \\
\hline ICS + LABA vs roflumilast & $0.83(0.68,1.01)$ \\
\hline ICS + LAMA + LABA vs roflumilast & $0.82(0.55,1.18)$ \\
\hline LAMA vs LABA & $0.88(0.77,1.01)$ \\
\hline ICS vs LABA & $0.96(0.84,1.08)$ \\
\hline Roflumilast + LABA vs LABA & $0.80(0.59,1.07)$ \\
\hline Roflumilast + LAMA vs LABA & $0.74(0.53,1.02)$ \\
\hline LABA + LAMA vs LABA & $0.96(0.67,1.34)$ \\
\hline ICS + LABA vs LABA & $0.82(0.74,0.91)$ \\
\hline ICS + LAMA + LABA vs LABA & $0.82(0.56,1.14)$ \\
\hline ICS vs LAMA & $1.09(0.93,1.26)$ \\
\hline Roflumilast + LABA vs LAMA & $0.91(0.65,1.25)$ \\
\hline Roflumilast + LAMA vs LAMA & $0.84(0.62,1.13)$ \\
\hline LABA + LAMA vs LAMA & $1.09(0.78,1.48)$ \\
\hline ICS + LABA vs LAMA & $0.94(0.8 \mathrm{I}, \mathrm{I} .07)$ \\
\hline ICS + LAMA + LABA vs LAMA & $0.92(0.65,1.27)$ \\
\hline Roflumilast + LABA vs ICS & $0.84(0.61,1.15)$ \\
\hline Roflumilast + LAMA vs ICS & $0.78(0.55,1.08)$ \\
\hline LABA + LAMA vs ICS & $\mathrm{I} .00(0.69, \mathrm{I} .4 \mathrm{I})$ \\
\hline ICS + LABA vs ICS & $0.86(0.76,0.98)$ \\
\hline ICS + LAMA + LABA vs ICS & $0.85(0.59,1.21)$ \\
\hline Roflumilast + LAMA vs roflumilast + LABA & $0.95(0.59,1.45)$ \\
\hline LABA + LAMA vs roflumilast + LABA & $1.22(0.76,1.89)$ \\
\hline ICS + LABA vs roflumilast + LABA & $1.05(0.76,1.42)$ \\
\hline LAMA + ICS + LABA vs roflumilast + LABA & $\mathrm{I} .04(0.64, \mathrm{I} .6 \mathrm{I})$ \\
\hline LABA + LAMA vs roflumilast + LAMA & $1.32(0.83,1.99)$ \\
\hline ICS + LABA vs roflumilast + LAMA & $\mathrm{I} .14(0.80,1.55)$ \\
\hline ICS + LAMA + LABA vs roflumilast + LAMA & $1.12(0.70,1.71)$ \\
\hline$I C S+L A B A$ vs LABA + LAMA & $0.88(0.6 \mathrm{I}, \mathrm{I} .23)$ \\
\hline ICS + LAMA + LABA vs LABA + LAMA & $0.86(0.61,1.18)$ \\
\hline ICS + LAMA + LABA vs ICS + LABA & $0.99(0.68,1.40)$ \\
\hline
\end{tabular}

Abbreviations: COPD, chronic obstructive pulmonary disease; ICS, inhaled corticosteroids; LABA, long-acting beta agonists; LAMA, long-acting antimuscarinic drugs; MTC, mixed-treatment comparison.
Appendix Table 10 Absolute treatment effects obtained from the random-effects MTC model including previously unpublished roflumilast data (M2-I I I trial) ${ }^{28}$

\begin{tabular}{ll}
\hline Treatment & Absolute treatment effect $(95 \% \mathrm{Cl})$ \\
\cline { 2 - 2 } & Original MTC analysis \\
\hline Placebo & $1.18(1.15,1.21)$ \\
Roflumilast & $0.98(0.83,1.15)$ \\
LABA & $0.98(0.89,1.09)$ \\
LAMA & $0.87(0.78,0.95)$ \\
ICS & $0.94(0.84,1.05)$ \\
Roflumilast + LABA & $0.79(0.57,1.07)$ \\
Roflumilast + LAMA & $0.73(0.53,1.00)$ \\
LABA + LAMA & $0.94(0.66,1.31)$ \\
ICS + LABA & $0.8 I(0.72,0.90)$ \\
ICS + LAMA + LABA & $0.80(0.56,1.11)$ \\
\hline
\end{tabular}

Note: Absolute treatment effects are expressed as mean exacerbations experienced per patient per patient-year.

Abbreviations: COPD, chronic obstructive pulmonary disease; ICS, inhaled corticosteroids; LABA, long-acting beta agonists; LAMA, long-acting antimuscarinic drugs; MTC, mixed-treatment comparison.

Appendix Table II Probability each of the 15 treatments (ie, 5 single treatments plus 10 combinations of active treatments) for management of COPD is best, obtained on the basis of the additive main effects model considered in our secondary MTC analysis. This table includes previously unpublished roflumilast data (M2-I I trial) ${ }^{28}$

\begin{tabular}{ll}
\hline Treatment & Probability treatment is best \\
\hline Placebo & 0.000 \\
Roflumilast & 0.000 \\
LABA & 0.000 \\
LAMA & 0.000 \\
ICS & 0.000 \\
Roflumilast + LABA & 0.000 \\
Roflumilast + LAMA & 0.000 \\
Roflumilast + ICS & 0.000 \\
LABA + LAMA & 0.000 \\
LABA + ICS & 0.000 \\
LAMA + ICS & 0.000 \\
Roflumilast + LABA + LAMA & 0.000 \\
Roflumilast + LABA + ICS & 0.000 \\
LAMA + LABA + ICS & 0.003 \\
Roflumilast + LABA + LAMA + ICS & 0.997 \\
\hline
\end{tabular}

Abbreviations: COPD, chronic obstructive pulmonary disease; ICS, inhaled corticosteroids; LABA, long-acting beta agonists; LAMA, long-acting antimuscarinic drugs; MTC, mixed-treatment comparison. 
Appendix Table 12 Estimated rate ratios and $95 \% \mathrm{Cl}$ for the effects of specific pairs of treatment combinations, produced by the additive main effects model considered in our MTC analysis including previously unpublished data (M2-III $)^{28}$

\begin{tabular}{lll}
\hline Treatment vs comparator & \multicolumn{2}{l}{$\begin{array}{l}\text { Additive main effects } \\
\text { model }\end{array}$} \\
\cline { 2 - 3 } & Rate ratio & $\mathbf{9 5 \%} \mathbf{~ C I}$ \\
\hline $\begin{array}{l}\text { LABA plus ICS plus roflumilast vs } \\
\text { LABA plus ICS }\end{array}$ & 0.82 & $0.73-0.93$ \\
$\begin{array}{l}\text { LABA plus ICS plus LAMA vs } \\
\text { LABA plus ICS plus roflumilast }\end{array}$ & 0.90 & $0.77-1.05$ \\
$\begin{array}{l}\text { LABA plus ICS plus LAMA plus } \\
\text { roflumilast vs LABA plus ICS plus LAMA }\end{array}$ & 0.82 & $0.73-0.93$ \\
$\begin{array}{l}\text { LAMA plus LABA plus roflumilast vs } \\
\text { LABA plus LAMA }\end{array}$ & 0.82 & $0.73-0.93$ \\
$\begin{array}{l}\text { LAMA plus LABA plus ICS vs } \\
\text { LAMA plus LABA plus roflumilast }\end{array}$ & 1.00 & $0.86-1.15$ \\
\hline
\end{tabular}

Abbreviations: COPD, chronic obstructive pulmonary disease; ICS, inhaled corticosteroids; LABA, long-acting beta agonists; LAMA, long-acting antimuscarinic drugs; MTC, mixed-treatment comparison.

\section{Publish your work in this journal}

Clinical Epidemiology is an international, peer-reviewed, open access journal focusing on disease and drug epidemiology, identification of risk factors and screening procedures to develop optimal preventative initiatives and programs. Specific topics include: diagnosis, prognosis, treatment, screening, prevention, risk factor modification, systematic

Submit your manuscript here: http://www.dovepress.com/clinical-epidemiology-journal
Dovepress

reviews, risk \& safety of medical interventions, epidemiology \& biostatical methods, evaluation of guidelines, translational medicine, health policies \& economic evaluations. The manuscript management system is completely online and includes a very quick and fair peer-review system, which is all easy to use. 